\title{
The Research Foci of Computing Research in South Africa as Reflected by Publications in the South African Computer Journal
}

\author{
Paula Kotzé, Alta van der Merwe \\ Meraka Institute \& University of South Africa, Pretoria \\ paula.kotze@meraka.org.za, alta@meraka.org.za
}

\begin{abstract}
The South African Computer Journal, better known as SACJ, has, for the last nineteen years, been one of the most pertinent publications for the computing discipline within the South African milieu. In this paper we reflect on the topics of research articles published in SACJ over its first 40 volumes of the journal using the ACM Computing Classification Scheme as basis. In our analysis we divided the publications into three cycles of more or less six years in order to identify significant trends over the history of the journal. We also used the same classification scheme to analyse the publication trends of various South African tertiary education and research institutions.
\end{abstract}

\section{CATEGORIES AND SUBJECT DESCRIPTORS}

A.1 [Introductory and Survey], K.2 [History of Computing]

\section{KEYWORDS}

South African Computer Journal history; South African Computer Journal publication topics; South African tertiary and research institution publication trends.

\section{INTRODUCTION}

Computing is used in almost every application domain and influence progress in engineering, science, business, and many other areas. In this paper we adopt the term computing as defined by The Association for Computing Machinery (ACM), The Association for Information Systems (AIS), and the Computer Society (IEEE-CS) [12]. They define computing to mean 'any goal-oriented activity requiring, benefiting from, or creating computers', including 'designing and building hardware and software systems for a wide range of purposes; processing, structuring, and managing various kinds of information; doing scientific studies using computers; making computer systems behave intelligently; creating and using communications and entertainment media; finding and gathering information relevant to any particular purpose', etc. [12: p. 9]. Computing is positioned to include a variety of sub-disciplines prominent today: computer engineering, computer science, information systems, information technology, and software engineering.

Computing research is a mechanism through which the computing field initiates its advances [5]. With the immense growth in the last decade of technology environments such as the Internet and World Wide Web, there has been new interest from governing bodies to support research in computing. For example, Goth [6] reports on the new boost of computer science (CS) research in the USA where recent government-sponsored reports have emphasized basic CS research needs, which were lacking for several years. In Europe, the European Parliament has approved a $€ 50.5 \mathrm{bn}$ plan to boost science research in Europe where information technology gets the biggest chunk of funding, with a $€ 9.1 \mathrm{bn}$ euro budget [2].

In South Africa, there are currently several initiatives that support research in the field of Computing. The National Research and Development Strategy [7] identified information and communication technology (ICT) as a key mission to bring improved quality of life an enhance the economic competitiveness of industry. The Meraka Institute was established in 2005 as a national strategic initiative from President Mbeki's 2002 State of the Nation Address, with the major objective to facilitate national economic and social development through human capital development and needsbased research and innovation, leading to products and services based on ICT [8].

In 2007 government once again raised its concern with regard to the growth of computing skills when Minister Naledi Pandor, Minister of National Education, invited the formal and informal ICT education sector, the ICT industry and other employers of ICT graduates to attend the Colloquium on ICT Skills Development. The outcome of this gathering was the Birchwood Declaration [3] containing a call to the South African Institute for Computer Scientists and Information Technologists (SAICSIT) and the Computer Society of South Africa (CSSA) communities to arrange a biannual think-tank to bring together academic, research organization, industry and government leaders to set strategic goals for ICT research and innovation. The first of these is to be hosted as a Grand Challenge Workshop at the Annual Conference of SAICSIT in October 2008 [11]. 
Computing innovation and research is therefore at the forefront of research and development strategies in South Africa and one question that arise is related to the prospect of the publication of research outcomes. There are various recognized international journals in which researchers within the field of computing can publish. But because of the varied nature of these journals, they give a fragmented view of research done in South Africa. Within South Africa there are a limited number of options for researchers in computing with regard to accredited journals that qualify for subsidy purposes as defined by government, and which can be used to showcase the research focus of computing in a more coherent way. The South African Computer Journal (SACJ) is widely recognized as the primary publication medium for computing in South Africa aiming to fulfil this role. According to the journal's published scope the purpose of the journal is to publish original research articles in the fields of Computer Science and Information Systems [10].

Quaestiones Informaticae (QI) was the forerunner to SACJ. In 1989 Derrick Kourie from the University of Pretoria took over as editor of QI and in his very first issue as editor (Vol. 6, No. 4, April 1989) he announced that he was changing the name of the journal to "The South African Computer Journal'. The first volume of SACJ was published in January 1990 as a paper-based journal. From 2001 onwards the publication also became electronically available through Sabinet [4]. Derrick Kourie was therefore the editor of SACJ from its inception until the most recent issue (Vol. 40, June 2008). SACJ is now entering a new era with the appointment of Lucas Venter from the University of South Africa as the new editor taking over from Derrick Kourie.

In the June 2008 edition of SACJ, Roode [9] put out an invitation to authors to consider the careful analysis of their historical roots. According to him 'only through careful analysis could we hope to understand our history, and make it part of our armoury to find the answers to the problems confronting us'. Although Roode [9] refers to the history of information systems and computer science, we believe that this could be extended to the history of what we have done and published in South Africa through our main computing publication, SACJ.

Furthermore, there are researchers in South Africa who have expressed the view that SACJ limit the scope of articles that is included in the journal to be only articles that tend to be of a more pure computer science nature and that applied fields from related information technology (IT) fields are neglected.

It is therefore an appropriate time to look at the history of SACJ and the articles it has published since its inception in 1990. The purpose of such a review would be fourfold: to get a picture of our history by analysing the publication trends in SACJ over its first 40 editions, to provide a profile of publications accepted for publication in SACJ, to provide the new editor with information that can serve as basis to ensure that the articles published in future editions of SACJ is a representation of the research done in South Africa, and finally to serve as a tribute to its first editor by providing a summary of the work published under his leadership.

Section 2 of this paper provides detail on the data collection and an overview of the methods used for the classification of research articles. In section 3 we discuss the results obtained from analysing the history of what have been published in SACJ. This data is discussed with regards to the publication trends within computing subject descriptors, prominent subcategories and changing trends over the period of the first 40 volumes of SACJ. Section 4 discusses the publication trends of the different South African tertiary education and research institutions in SACJ since its inception. Section 5 summarises and concludes.

\section{BACKGROUND}

\subsection{Data Capturing}

As mentioned previously, the first edition of SACJ was published in January 1990. Since 1990, there have been 40 editions up to the June 2008 edition, which is on average two editions per year.

In order to capture information related to all the articles published in the 40 editions, a Microsoft Access database was created with 11 normalized tables. For each article the article title, authors, institution, type of article, classification and keywords were captured. Not all articles published in SACJ were research articles; the articles included different types of articles such as communications, guest contributions and technical notes. Although all these types of articles were captured in the database, our focus was on the research articles published and in this paper we only report on the 344 articles that can been classified as research contributions.

In the database there was a one-to-many relationship between an article and an author, which meant that each article could have one or more author. Implicitly that means that each article could have more than one institution that it is associated with, since authors relating to a specific article do not necessarily belong to the same institution. Therefore more than 344 (number of research articles) instances were captured to represent the relationship between articles and institutions.

Articles were classified according to the ACM Computing Classification System [1] (see discussion in section 2.2).

Queries were generated from Microsoft Access and the results were imported into Microsoft Excel from where the data was processed further and visualised for presentation.

\subsection{Classifying the Research Articles}

The classification system used to classify articles into categories was the 1998 version of the ACM Computing Classification System [1]. The ACM Computing Classification System was first released in 1964 with the latest release in 1998. We selected this classification system because the articles in the first 33 volumes (15 years) of SACJ were all categorized by the authors according to this system. Rather than using another system, we preferred to use this system where the author, who knows the content of the article best, selected the appropriate category for the article. The articles that appeared in the last 7 volumes of the journal were no longer classified according to the ACM Computing Classification System. Interpretation was 
therefore only necessary for these articles, where we selected the most appropriate categories according to the content of the articles.

The ACM classification system is a four-level tree structure that has three coded levels of categories and a non-coded level of subject descriptors (usually appearing at the fourth level). For example:

\section{Categories: \\ H. INFORMATION SYSTEMS \\ H.2. DATABASE MANAGEMENT \\ H.2.3 Languages \\ Subject descriptor: Query languages}

The three levels were captured in the data base and each article was linked with at least the first and second category, according to availability of lower levels. In cases where there were not a third level available, the second level classification was also used as third level.

The top level of the ACM Computing Classification System 1998 consists of 11 categories:

- A. General Literature

- B. Hardware

- C. Computer Systems Organization

- D. Software

- E. Data

- F. Theory of Computation

- G. Mathematics of Computing

- H. Information Systems

- I. Computing Methodologies

- J. Computer Applications

- K. Computing Milieux.

\subsection{Analysis of Data}

We analysed the data collected on the research articles published in SACJ from two perspectives: research topics according to the classification scheme and publication trends within South African tertiary education institutions and research councils.

For each of these we analysed the research articles published according to the total number of articles published over all years and also for trends during different eras. These eras were determined by subdividing the volumes into three groups of six years each, with the last group covering 6.5 years:

1. Volumes 1 to 15 , published from 1990 to 1995 . A total of 125 research articles were published during this period.

2. Volumes 16 to 27 , published from 1996 to 2001. A total of 103 research articles were published during this period.

3. Volumes 28 to 40, published from 2002 to 2008. A total of 116 research articles were published during this period.

Section 3 discusses the findings on the research topics according to the classification scheme and section 4 the publication trends within South African tertiary education institutions research councils.

\section{RESEARCH ARTICLES ACCORDING TO CATEGORY}

The first subsection gives an overview of the entire set of 344 articles published according to the 11 top level categories of the ACM Computing Classification System.

\subsection{All Research Articles}

In Table 2 a summary is given of the number (expressed in percentages) of research articles published overall and per era according to the categories.

Table 2. Research articles as percentages of the total number of articles overall and per era

\begin{tabular}{|c|c|c|c|c|}
\hline CATEGORY & $\begin{array}{l}\% \\
\text { All } \\
\text { year } \\
\text { S }\end{array}$ & $\begin{array}{l}\% \\
1990 \\
- \\
1995\end{array}$ & $\begin{array}{l}\% \\
1996 \\
- \\
2001\end{array}$ & $\begin{array}{l}\% \\
2002- \\
2008\end{array}$ \\
\hline A. General Literature & 1.74 & 3.20 & 0.97 & 0.86 \\
\hline B. Hardware & 2.91 & 1.60 & 2.91 & 4.31 \\
\hline $\begin{array}{l}\text { C. Computer Systems } \\
\text { Organization }\end{array}$ & 7.27 & 8.80 & 4.85 & 7.76 \\
\hline D. Software & $\begin{array}{l}19.4 \\
8\end{array}$ & 22.40 & 24.27 & 12.07 \\
\hline E. Data & 1.16 & 0.80 & 0.97 & 1.72 \\
\hline $\begin{array}{l}\text { F. Theory Of } \\
\text { Computation }\end{array}$ & 7.85 & 6.40 & 7.77 & 9.48 \\
\hline $\begin{array}{l}\text { G. Mathematics of } \\
\text { Computing }\end{array}$ & 2.91 & 3.20 & 3.88 & 1.72 \\
\hline H. Information Systems & $\begin{array}{l}16.5 \\
7\end{array}$ & 16.80 & 14.56 & 18.10 \\
\hline $\begin{array}{l}\text { I. Computing } \\
\text { Methodologies }\end{array}$ & $\begin{array}{l}15.9 \\
9\end{array}$ & 19.20 & 13.59 & 14.66 \\
\hline $\begin{array}{l}\text { J. Computer } \\
\text { Applications }\end{array}$ & 2.91 & 0.80 & 0.00 & 7.76 \\
\hline K. Computing Milieux & $\begin{array}{l}21.2 \\
2\end{array}$ & 16.80 & 26.21 & 21.55 \\
\hline
\end{tabular}

Figure 1 illustrates the publication trends (as total article counts) per top level category over all 40 volumes of SACJ between 1990 and 2008. 


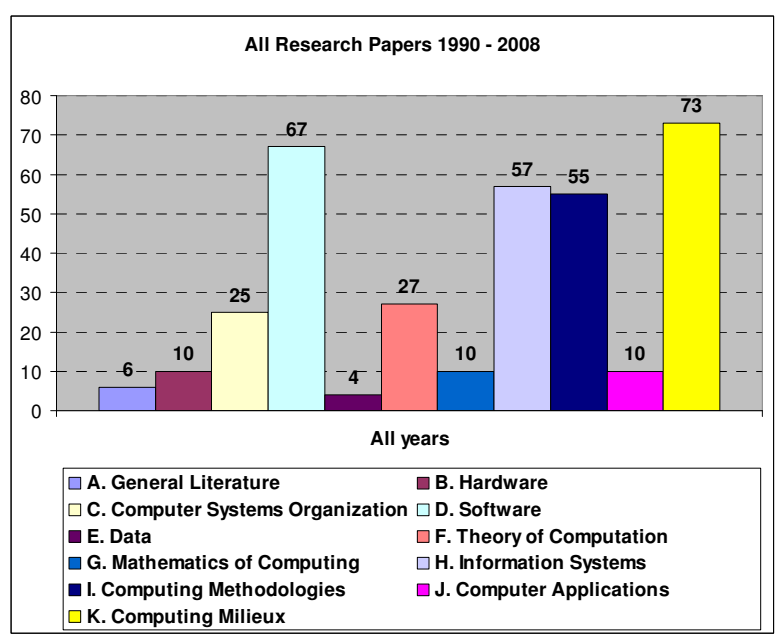

Figure 1. Research article counts per main category for period 1990 to 2008 (all 40 volumes)

According to the data presented in Figure 1, more than $73 \%$ of articles published in SACJ since its inception were classified to belong to only four categories, namely:

1. Computing Milieux

2. Software

3. Information Systems

4. Computing Methodologies.

From the remaining articles, $15 \%$ were published in either Theory of Computation or Computer Systems Organization, whilst the rest of the categories each had less than $3 \%$ of the articles.

Figures 2 and 3 provide a graphical view of articles published according to the different eras. Figure 2 breaks the data on top level categories provided in Figure 1 down into the three eras.

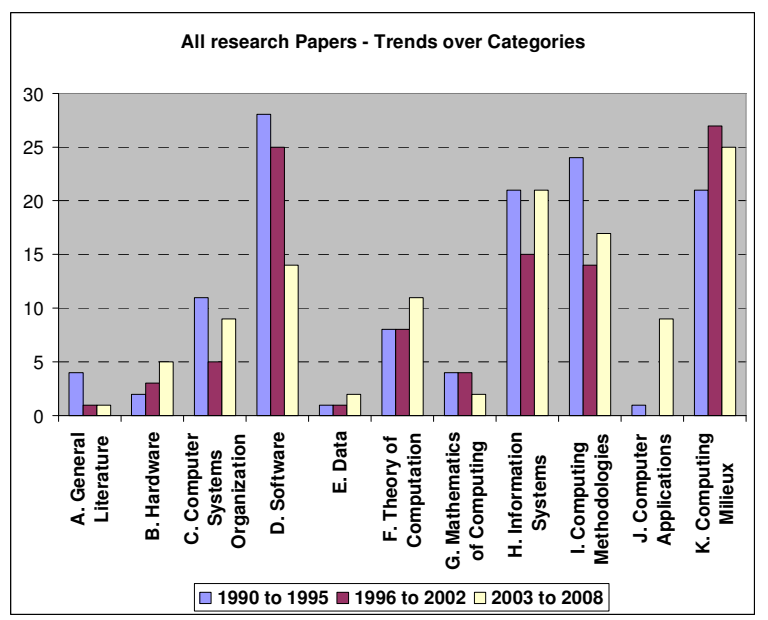

Figure 2. Research articles per main category for period 1990 to 2008 per era

Figure 3 groups the publication trends (as total article counts) per era (1990 to 1995,1996 to 2001,2002 to 2008) giving the article counts for the top level categories for each era.

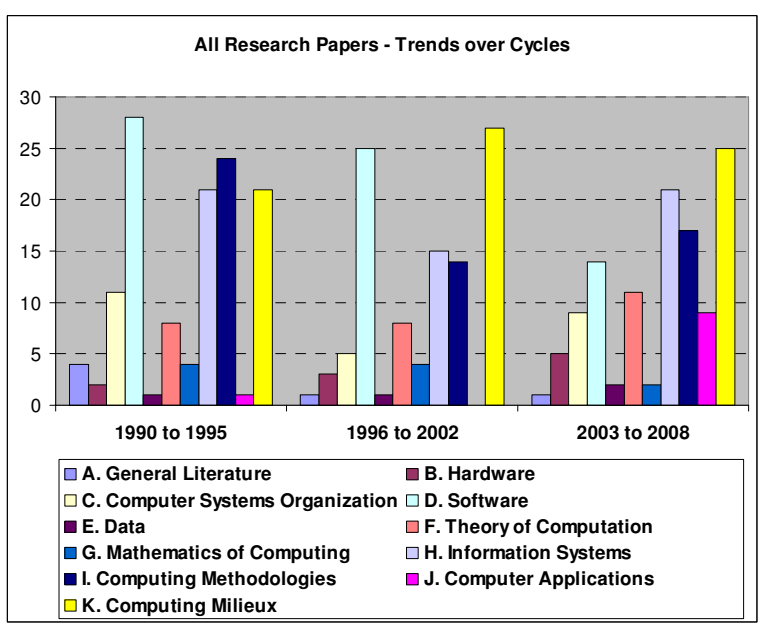

Figure 3. Research article counts per era according to top level category

Some interesting observations from the data are:

- Software has been the most prominent category during 1990 to 1995 , but has slowly declined to be ranked fourth during the period 2002 to 2008.

- Information Systems overtook Computing Methodologies in the middle era to be ranked second overall in the third era.

- Computing Milieux grew stronger than Information Systems in the middles era, and these two applied categories became the strongest overall in the last era.

- The strong re-emergence of Computer Applications in the third era.

Overall the data indicates that there has been some shift towards the applied fields between the first and third era. The naming of the top level categories is, however, not very descriptive in explaining the trends, and we therefore have to look at the lower level categories to provide a better founded analysis. In the next section we analyse the trends within the 6 most prominent top level categories to sub-category level. We also include a short discussion on an emerging top-level category.

\subsection{Prominent Subcategories}

\subsubsection{Computing Milieux}

Category K, Computing Milieux, has overall been the strongest category and has been ranked first in two of the three eras. The category consists of 10 sub-categories, namely:

- K.0 General

- $\quad$ K.1 The Computer Industry

- K.2 History Of Computing

- K.3 Computers And Education

- $\quad$ K.4 Computers And Society

- K.5 Legal Aspects of Computing

- K.6 Management of Computing And Information Systems

- $\quad$ K.7 The Computing Profession

- K.8 Personal Computing

- K.m Miscellaneous. 


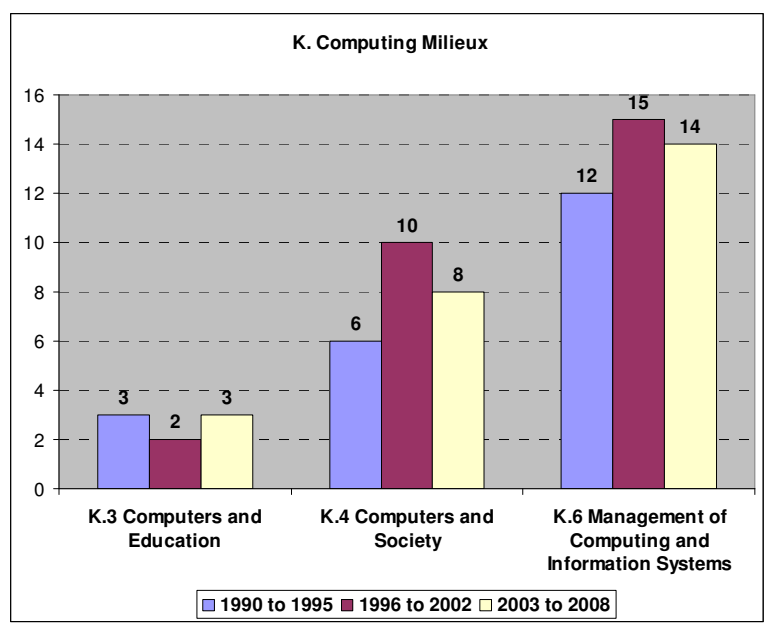

Figure 4. Subcategories within K. Computing Milieax

Figure 4 illustrates the publication trends (as article counts) for articles published in SACJ in this category. The following can be noted:

- Only 3 of the 8 subcategories are covered in SACJ: Computers and Education, Computers and Society and Management of Computing and Information Systems, with the latter the strongest subcategory over all the eras.

- The data indicates no drastic changes in publication patterns (article counts) within the three sub-categories published on in SACJ over the eras.

\subsubsection{Software}

Category D, Software, overall has the second largest number of articles published in SACJ and has been at its strongest level during the middle era (1996 to 2001). The category consists of 6 subcategories, namely:

- D.0 General

- D.1 Programming Techniques

- D.2 Software Engineering

- D.3 Programming Languages

- D.4 Operating Systems

- D.m Miscellaneous.

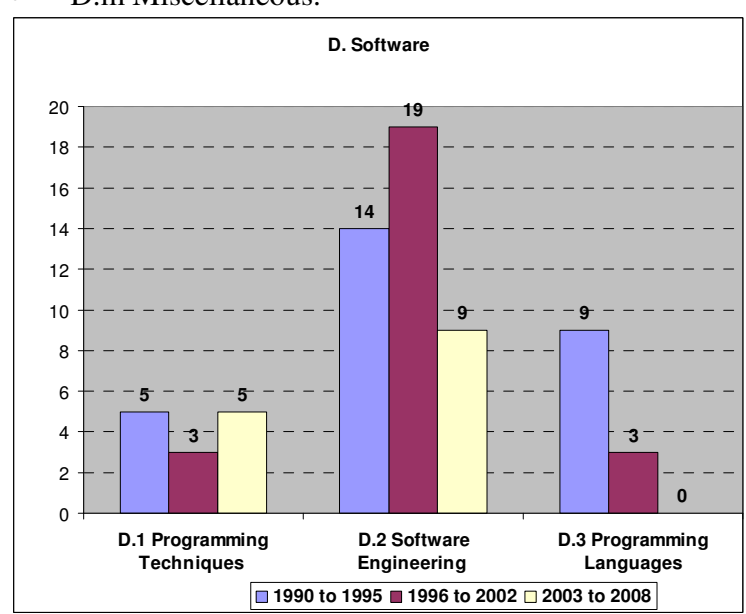

Figure 5. Subcategories within D. Software
Figure 5 illustrate the publication trends (as article counts) for articles published in SACJ in this category. The following are trends worth mentioning:

- Only 3 of the 5 subcategories are covered in SACJ, namely Programming Techniques, Software Engineering and Programming Languages.

- Software Engineering was the strongest subcategory over all the years, and particularly strong in the middle era (1996 to 2001), with a more than $50 \%$ decline in the last era as compared to the middle era.

- Programming Languages declined significantly over the three eras and had no articles in the last era (2002 to 2008).

\subsubsection{Information Systems}

Category H, Information Systems, has overall been the third strongest category and is ranked second in the last era. The category consists of 7 sub-categories, namely:

- H.0 General

- H.1 Models and Principles

- H.2 Database Management

- H.3 Information Storage and Retrieval

- H.4 Information Systems Applications

- H.5 Information Interfaces and Presentation (E.G., HCI) - H.m Miscellaneous.

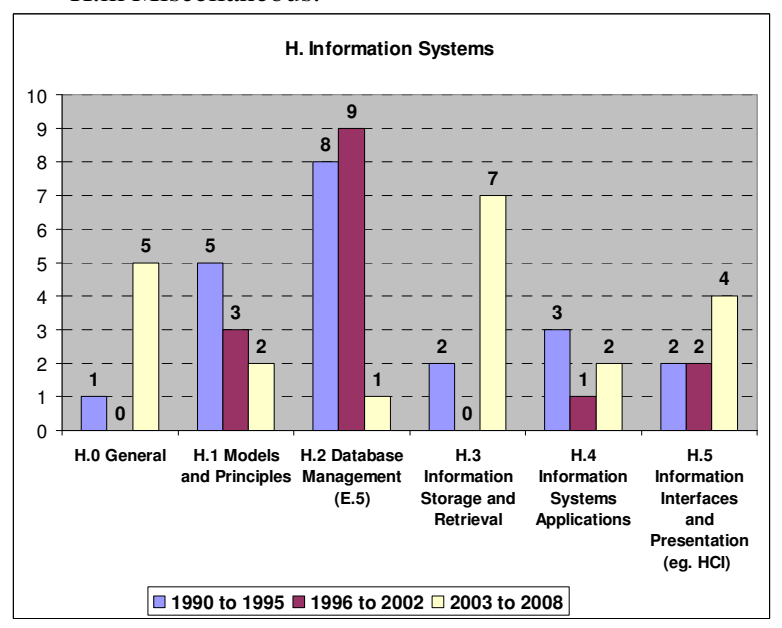

Figure 6. Subcategories within H. Information Systems

Figure 6 illustrate the publication trends (as article counts) for articles published in SACJ in this category. The following are noted:

- All the subcategories apart from Miscellaneous were covered in SACJ.

- Database Management has been very strong in the first two eras, but has diminished to a single article in the last era (2002 to 2008).

- There has also been a steady decline in the number of article published under the topic Models and Principles.

- Growth patterns are observable for General, Information Storage and Retrieval (strong and both instances) and Information Interfaces and Presentation.

\subsubsection{Computing methodologies}

Category I, Computing Methodologies, has overall been the fourth strongest category. It was ranked second in the first 
era (after software) and is ranked third in the last era. The category consists of 9 sub-categories, namely:

- I.0 General

- I.1 Symbolic and Algebraic Manipulation

- I.2 Artificial Intelligence

- I.3 Computer Graphics

- I.4 Image Processing and Computer Vision

- I.5 Pattern Recognition

- I.6 Simulation and Modelling

- $\quad$ I.7 Document and Text Processing

- I.m Miscellaneous.

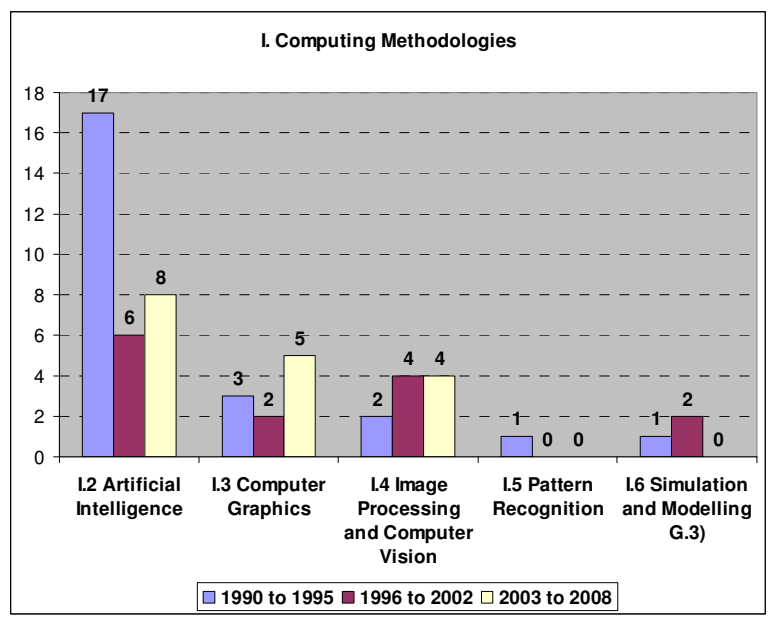

Figure 7. Subcategories within I. Computing Methodologies

Figure 7 illustrate the publication trends (as article counts) for articles published in SACJ in this category. The following can be noted:

- Five of the nine sub-categories were covered in SACJ over all eras, whilst only three has been covered in the last era, namely Artificial Intelligence, Computer Graphics and Image processing and Computer Vision. The other two subcategories had only 4 articles in total over all the years.

- Artificial Intelligence peaked in the first era (1990 to 1995) and then declined but still had a fairly strong presence of eight articles in the last era.

\subsubsection{Theory of Computation}

Category F, Theory of Computation, is ranked fifth overall, and had a steady increase in number of articles published over all three eras. The category consists of 6 sub-categories, namely:

- F.0 General

- F.1 Computation by Abstract Devices

- F.2 Analysis of Algorithms and Problem Complexity

- F.3 Logics and Meanings of Programs

- F.4 Mathematical Logic and Formal Languages

- F.m Miscellaneous.

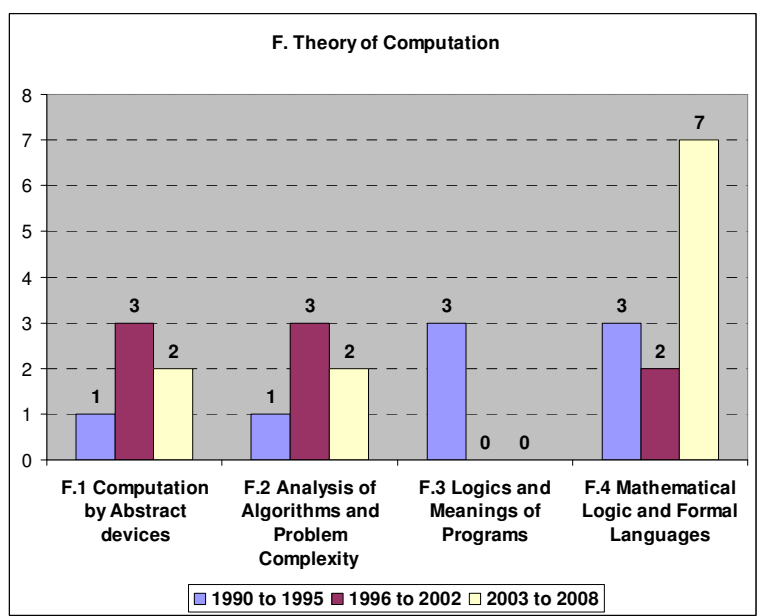

Figure 8. Subcategories within F. Theory of Computation Figure 8 illustrate the publication trends (as article counts) for articles published in SACJ in this category. The following can be noted:

- Articles were published in all four of the main subcategories (excluding General and Miscellaneous).

- The strongest subcategory is Mathematical Logic and Languages with a strong growth in the last era (2002 to 2008).

- The subcategory Logics and Meanings of Programs was prominent during 1990 to 1995 , but has disappeared since.

\subsubsection{Computer System Organisation}

Category C, Compute and Systems Organization is ranked sixth overall. The category consists of 7 subcategories, namely:

- C.0 General

- C.1 Processor Architectures

- C.2 Computer-Communication Networks

- C.3 Special-Purpose and Application-Based Systems

- C.4 Performance of Systems

- C.5 Computer System Implementation

- C.m Miscellaneous.

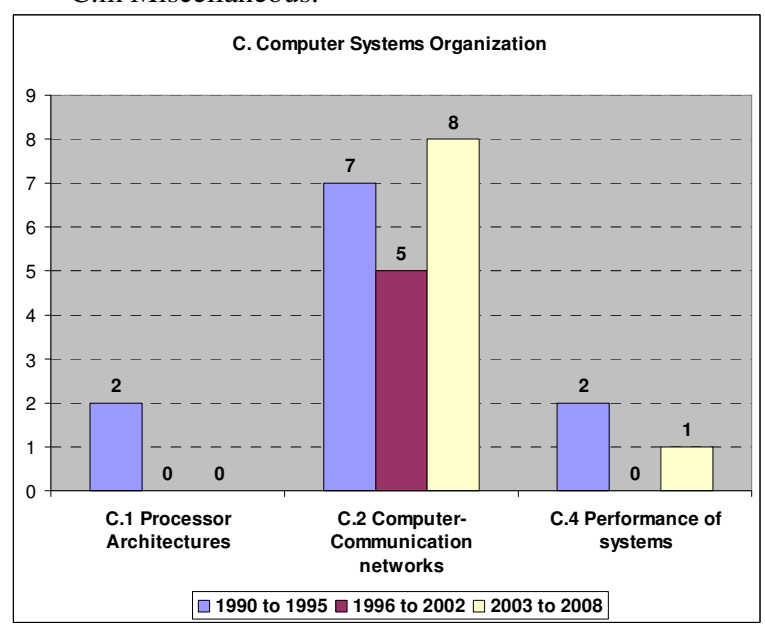

Figure 9. Subcategories within C. Computer System Organisation 
Figure 9 illustrate the publication trends (as article counts) for articles published in SACJ in this category. The following can be noted:

- Only three of the seven subcategories are covered in SACJ, with Computer Communication Networks by far the strongest over all the eras.

- The other two categories covered, Processor Architectures and Performance of Systems, have been declining of not covered in some eras.

\subsubsection{Computer Applications}

To conclude the discussion on prominent subcategories, we have included Category J, Computer Applications as special category, not because of its high ranking over all the eras, but because of its strong emergence in the last era. This category consists of 9 subcategories, namely:

- J.0 General

- J.1 Administrative Data Processing

- J.2 Physical Sciences and Engineering

- J.3 Life and Medical Sciences

- J.4 Social and Behavioural Sciences

- J.5 Arts and Humanities

- J.6 Computer-Aided Engineering

- J.7 Computers in Other Systems

- J.m Miscellaneous.

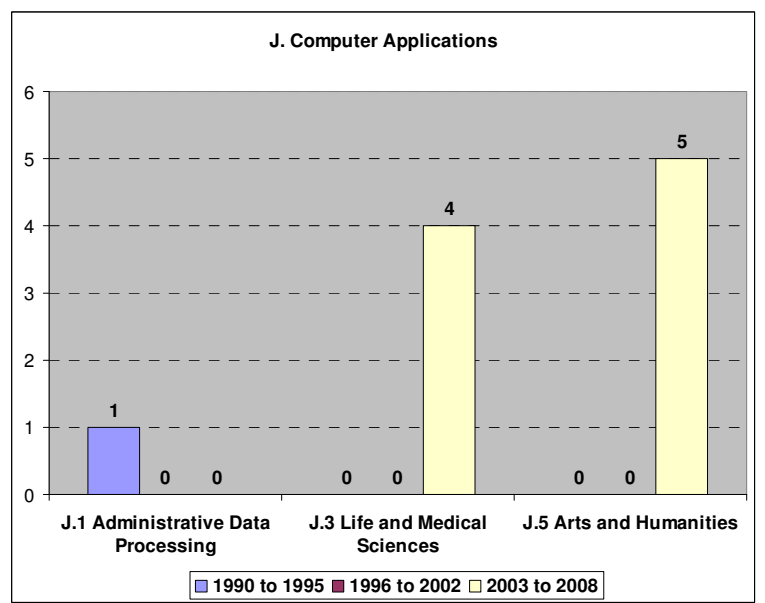

Figure 10. Subcategories within J. Computer Applications

Figure 10 illustrate the publication trends (as article counts) for articles published in SACJ in this category.

The following can be noted:

- Three of the nine subcategories have been covered by SACJ over all the eras. Administrative Data Processing had one article in the first era (1990 to 1995) but has not been covered since.

- Two other subcategories, Life and Medical Sciences and Arts and Humanities have strongly emerged in the last era (2002 to 2008) with no coverage in the first two eras.

\subsection{Trends in Sub-subcategories}

In section 3.2 the focus was only on second level categories. It is still possible to refine these categories to a lower level. Due to the large number of sub-subcategories (and the small number of article counts in the majority of them) we cannot include a discussion on all the sub-subcategories covered in SACJ. Therefore, concluding our discussion on research articles classified according to category, we will only look at a few interesting trends in the sub-subcategories. We limit our discussion to those that are growing, declining, is stable and some interesting peaks noticed over the eras. We also include detail on two categories that seemingly has stable subtopics, namely Computing Milieux and Software.

\subsubsection{Growing sub-subcategories}

In Figure 11, a graphical overview is given of the subcategories that have shown growth over the eras (with several of them only emerging in the last era (2002 to 2008)).

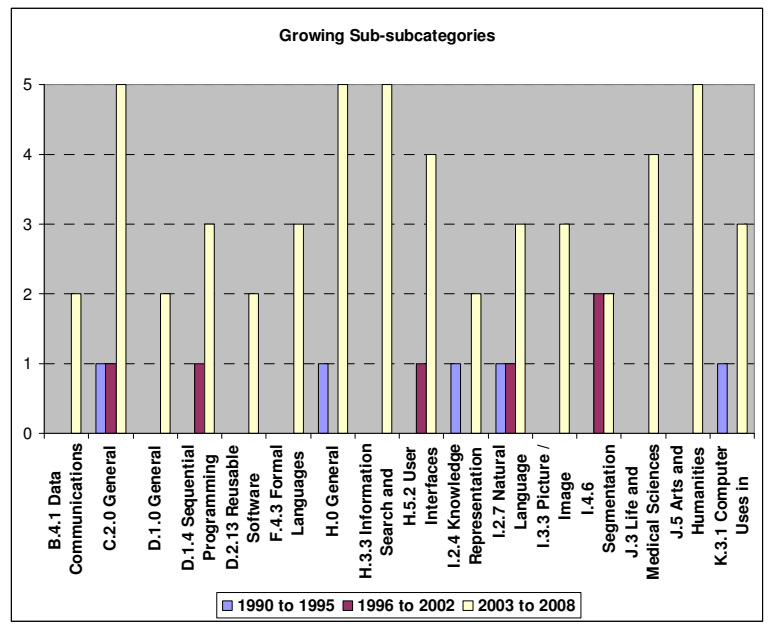

Figure 11. Growing sub-subcategories

The list of sub-subcategories that has grown, ordered according to article counts over all the eras (from highest to lowest), is:

- C.2.0 General (Computer Communication Networks)

- H.0 General (Information Systems)

- H.3.3 Information Search and Retrieval

- H.5.2 User Interfaces

- I.2.7 Natural Language Processing

- J.5 Arts and Humanities

- D.1.4 Sequential Programming

- I.4.6 Segmentation

- J.3 Life and Medical Sciences

- K.3.1 Computer Uses in Education

- F.4.3 Formal Languages

- I.2.4 Knowledge Representation Formalisms and Methods

- I.3.3 Picture / Image Generation

- B.4.1 Data Communications Devices

- D.1.0 General (Software)

- D.2.13 Reusable Software.

\subsubsection{Declining sub-subcategories}

Figure 11, ordered by sub-subcategory number, illustrates the declining sub-subcategories. 


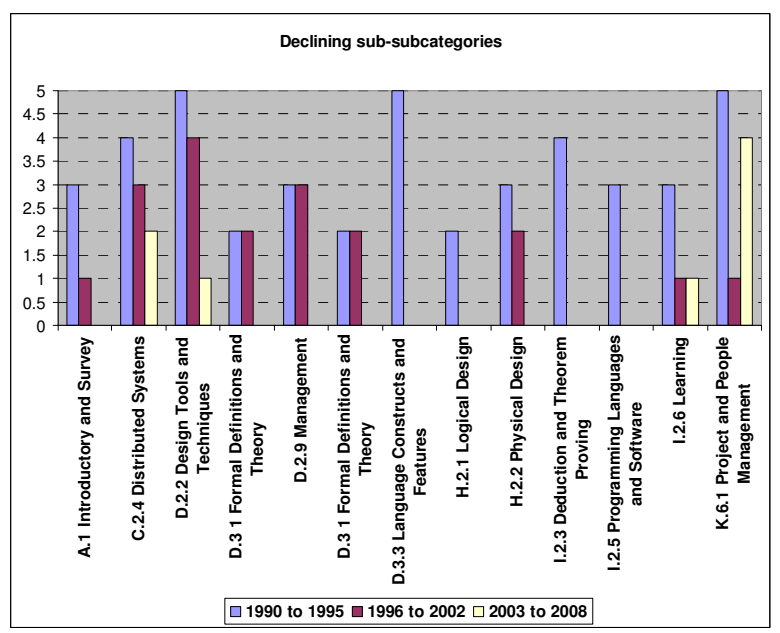

Figure 11. Declining sub-subcategories

There are a number of sub-subcategories where the number of articles published declined over the eras, with several of them disappearing in the second or last eras (1996 to 2001 or 2002 to 2008). The following list of disappearing article subsubcategories is ordered according to article counts over all the eras (from highest to lowest):

- D.2.2 Design Tools and Techniques

- K.6.1 Project and People Management

- C.2.4 Distributed Systems

- D.2.9 Management

- D.3.3 Language Constructs and Features

- H.2.2 Physical Design

- I.2.6 Learning

- A.1 Introductory and Survey

- D.3 1 Formal Definitions and Theory

- D.3 1 Formal Definitions and Theory

- I.2.3 Deduction and Theorem Proving

- I.2.5 Programming Languages and Software

- H.2.1 Logical Design

\subsubsection{Peaks and Stable Sub-subcategories}

There have also been four subcategories that had a fairly stable number of articles (between 1 and 3 article counts) over all the eras, as illustrated in Figure 12. These include:

- D.2.1 Requirements/Specifications

- F.4.1 Mathematical Logic

- H.1.2 User/Machine Systems

- $\quad$ I.2.1 Applications and Expert Systems

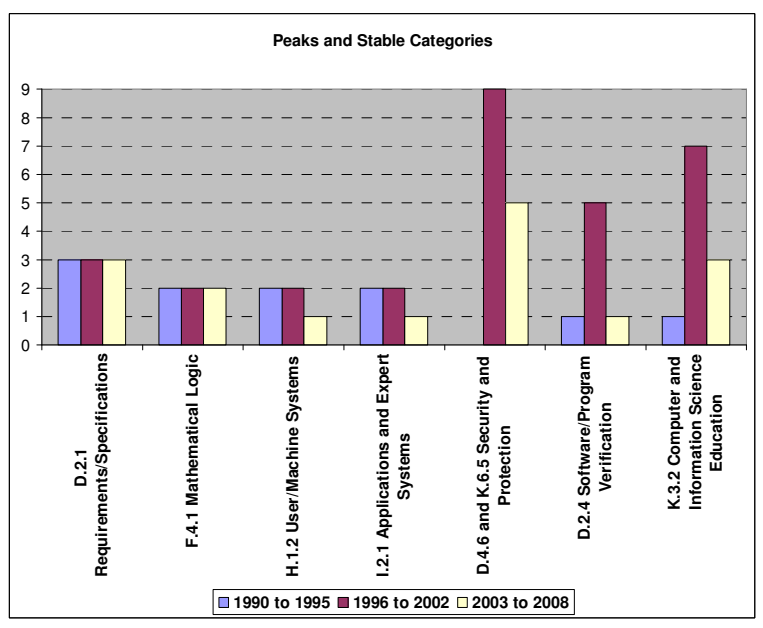

Figure 12. Peaks and stable sub-subcategories

Whilst section 3.3.1 noted growing sub-subcategories in the last era, it is also interesting to note the peaks in the second era (1996 to 2001). These peaks included:

- D.4.6 and K.6.5 Security and Protection, with a total of 9 articles during 1995 to 2001, from a total of 14 overall.

- D.2.4 Software/Program Verification, with a total of 5 articles during 1995 to 2001 , from a total of 7 overall.

- K.3.2 Computer and Information Science Education, with a total of 7 articles during 1995 to 2001, from a total of 11 overall.

\subsubsection{Computing Milieux}

We made the comment in section 3.2.1 that on the surface there does not seem to be a difference in publication patterns within the three sub-categories covered in SACJ, namely Computers and Education (K.3), Computers and Society (K.4) and Management of Computing and Information Systems (K.6). When we, however, break these categories down to sub-subcategory level, some definite changes in topic patterns can be observed.

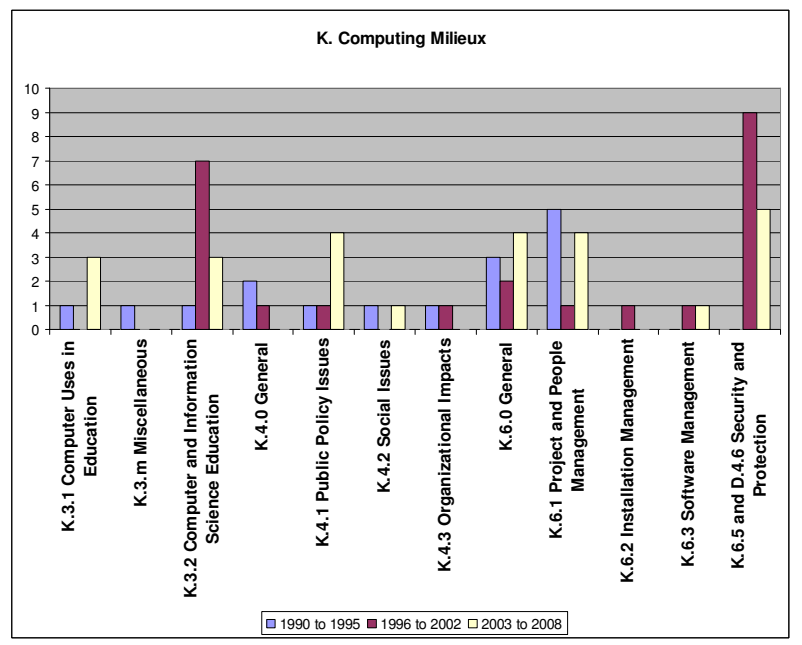

Figure 13: Publication Trends in sub-subcategories of Computing Milieux

Figure 13 illustrates the trends within these subcategories: 
- Within K.3 the data indicates that K.3.2 Computer and Information Science Education was the most prominent in the middle era whilst K.3.1 Computer Uses in Education was not covered at all in this era.

- Within K.4 there is a growth in the last era within the field of K.4.1 Public Policy Issues, whilst the other subsubcategories almost completely disappeared.

- Within K.6 there is a peak in the second era in K.6.5 Security and Protection, whilst K.6.1 Project and People Management were strong in the first and last eras.

There was therefore a shift in focus within the various subcategories of Computing Milieux with regards to the subsubcategory topics covered, although the total number of publications did not vary greatly over the eras within these sub-categories.

\subsubsection{Software Engineering}

Category D.2 Software Engineering, one of the subcategories in category D (Software), on the surface also seemed to have stable trends throughout. However, when one investigate the trends in the sub-subcategories for Software Engineering, as illustrated in Figure 14, it becomes clear that a variety of sub-subcategory topics contributed to the article counts over the three eras.

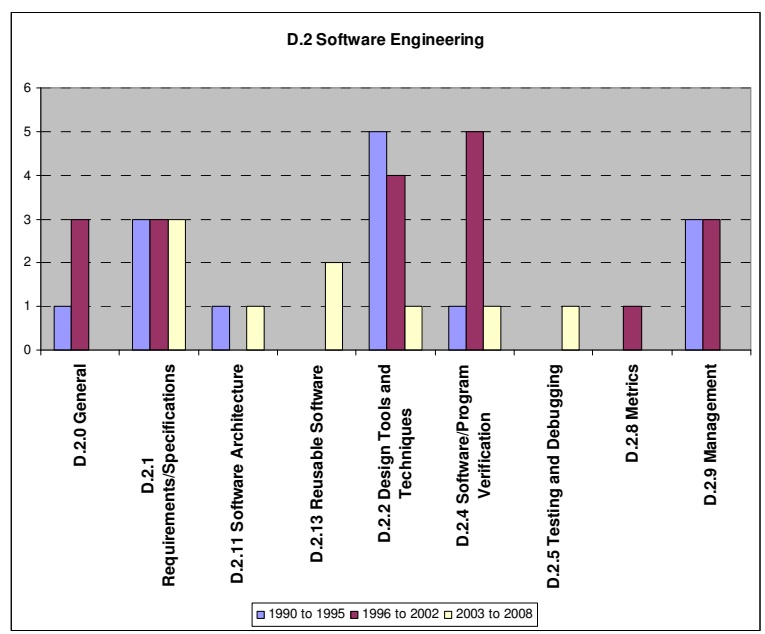

Figure 14. Publication Trends in sub-subcategories of Software Engineering

The major trends within these subcategories are:

- D.2.2 Design Tools and Techniques were the most prominent in the first era (1990 to 1995).

- D.2.4 Software/Program Verification had the highest article count in the middle ear followed closely by D.2.2 Design Tools and Techniques and three others after that.

- Quite a number of the sub-subtopics did not feature in all the eras.

This concludes our reflection on research articles according to the different categories in the ACM classification scheme. In the next section we will take a different angle on the same data when we analyse the publication trends according to the institutions that published in SACJ over the 40 volumes.

\section{RESEARCH ARTICLES ACCORDING TO INSTITUTION}

In this section we discuss the contribution of the South African tertiary education and research institutions to the articles published in SACJ. Although section 3 covered all the articles published in SACJ, we have decided to limit the discussion in this section to only the publications by the South African academic and research community. The reason for this is that all the other institutions that published in SACJ in total had contributed to a small number of the research articles published per institution.

In order to create a manageable distribution of articles we classified institutions according to their post-merger affiliations. We combined the totals of pre-merger institutions into the relevant merged institution's totals. In the remainder of this paper we will refer to all the institutions according to their post-merger acronyms (as listed in Table 3).

\subsection{All Research Articles over Institutions}

Figure 15 graphically depicts the total number of contributions (as article counts) for the various institutions that published in SACJ over all 40 volumes of the journal.

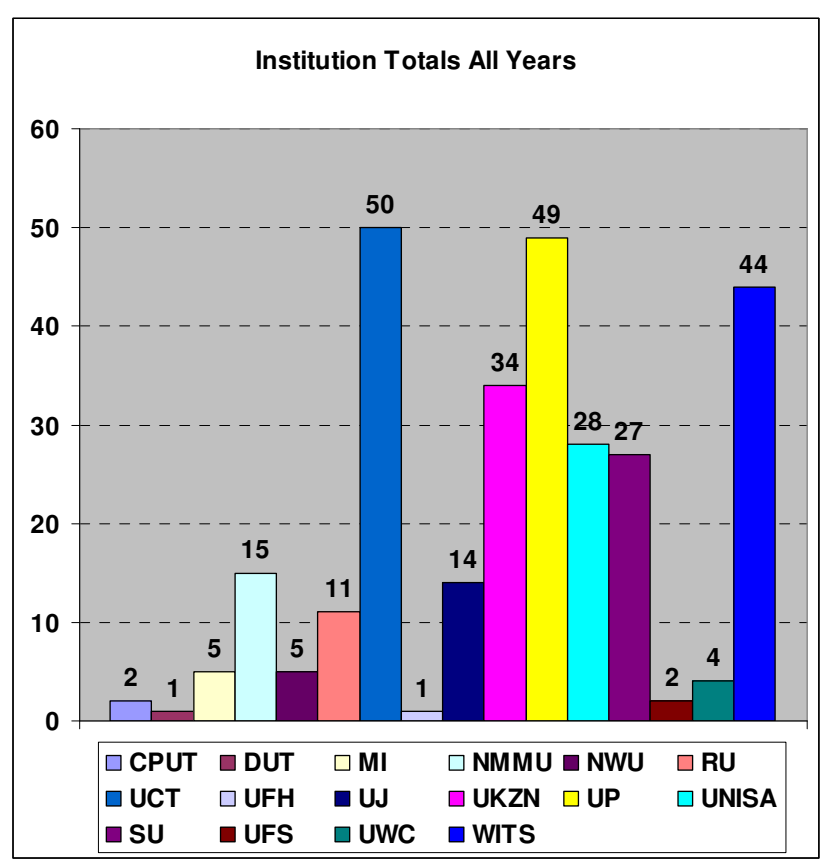

Figure 15. Research article counts per institution for period 1990 to 2008 (all 40 volumes)

UCT overall has the highest number of articles, followed by UP and WITS. Table 3 provides the contributions of the various institutions (as percentages) to the overall number of articles published for the entire period 1990 to 2008 and also for the three eras identified. The table is sorted by the total article counts over all 40 editions of SACJ.

Table 3. Research articles as percentages of the total number of articles overall and per era per institution

\begin{tabular}{|l|l|l|l|l|}
\hline Institution & All & 1990 - & 1996 - & 2002- \\
\hline
\end{tabular}




\begin{tabular}{|l|c|c|c|c|}
\hline & & $\mathbf{1 9 9 5}$ & $\mathbf{2 0 0 1}$ & $\mathbf{2 0 0 8}$ \\
\hline University of Cape Town (UCT) & 17.0 & 22.2 & 7.4 & 18.2 \\
\hline University of Pretoria (UP) & 16.7 & 7.4 & 18.5 & 23.6 \\
\hline $\begin{array}{l}\text { University of the Witwatersrand } \\
\text { (WITS) }\end{array}$ & 15.0 & 12.0 & 19.8 & 13.6 \\
\hline $\begin{array}{l}\text { University of KwaZulu-Natal / } \\
\text { University of Natal / University } \\
\text { of Durban-Westville (UKZN) }\end{array}$ & 11.6 & 14.8 & 17.3 & 3.6 \\
\hline $\begin{array}{l}\text { University of South Africa } \\
\text { (UNISA) }\end{array}$ & 9.5 & 8.3 & 11.1 & 9.1 \\
\hline Stellenbosch University (SU) & 9.2 & 15.7 & 3.7 & 6.4 \\
\hline $\begin{array}{l}\text { Nelson Mandela Metropolitan } \\
\text { University /University of Port } \\
\text { Elizabeth / Port Elizabeth } \\
\text { Technikon (NMMU) }\end{array}$ & 5.8 & 5.6 & 7.4 & 9.1 \\
\hline $\begin{array}{l}\text { University of Johannesburg / } \\
\text { Rand Afrikaans University (UJ) }\end{array}$ & 4.8 & 0.9 & 8.6 & 5.5 \\
\hline $\begin{array}{l}\text { Rhodes University (RU) } \\
\text { Meraka Institute / CSIR (MI) }\end{array}$ & 3.7 & 6.5 & 2.5 & 1.8 \\
\hline $\begin{array}{l}\text { Northwest University / } \\
\text { Potchefstroom University for } \\
\text { CHE (NWU) }\end{array}$ & 1.7 & 1.9 & 2.5 & 0.9 \\
\hline $\begin{array}{l}\text { University of the Western Cape } \\
\text { UWC) }\end{array}$ & 1.4 & 1.9 & 0.0 & 1.8 \\
\hline $\begin{array}{l}\text { Cape Peninsula University of } \\
\text { Technology / Cape Technikon } \\
\text { (CPUT) }\end{array}$ & 0.7 & 0.0 & 0.0 & 1.8 \\
\hline $\begin{array}{l}\text { University of the Free State / } \\
\text { University of the Orange Free } \\
\text { State (UFS) }\end{array}$ & 0.7 & 1.9 & 0.0 & 0.0 \\
\hline $\begin{array}{l}\text { Durban University of } \\
\text { Technologuy / M L Sultan } \\
\text { Technikon (DUT) }\end{array}$ & 0.3 & 0.0 & 1.2 & 0.0 \\
\hline University of Fort Hare (UFH) & 0.3 & 0.9 & 0.0 & 0.0 \\
\hline
\end{tabular}

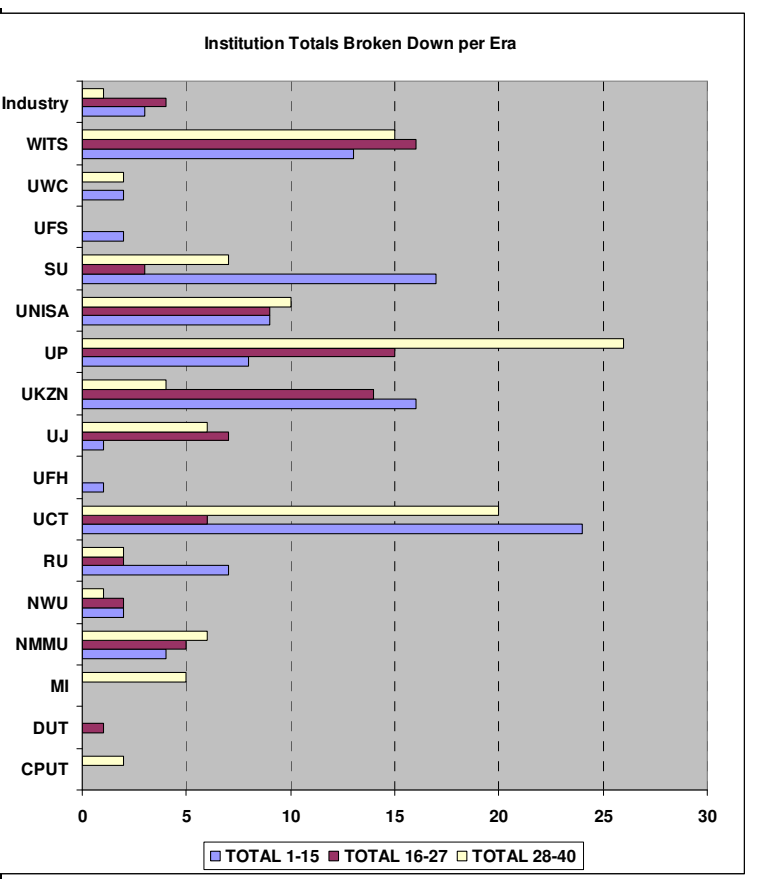

Figure 16 graphically depicts this information by article counts for the various institutions broken down into the three eras. We have also included the 'industry' component here to indicate its contribution.

Some significant trends from the data are:

- Growing: UP and MI.

- $\quad$ Stable: WITS, UNISA, NMMU.

- Declining: SU, UKZN, RU

- Decline and grow: UCT

- Grow and decline: UJ, Industry.

Table 4 illustrates the changes in the top 10 article count rankings during the three eras for the various institutions. According to the number of publications UP (growing) moved to position 1 in the third era recorded, with UCT (decline and grow) currently ranked second after dropping to seventh during the second era. The 'stable' group (WITS, UNISA, NMMU) has slowly moved up the ranking to make up the rest of the top 5 .

igure 16. Research article counts per institution broken down between the three eras

Table 4. Top 10 rankings as it changed during the three eras

\begin{tabular}{|l|l|l|l|}
\hline $\mathbf{1 9 9 0}-\mathbf{1 9 9 5}$ & $\mathbf{1 9 9 6 - 2 0 0 1}$ & $\mathbf{2 0 0 2}-\mathbf{2 0 0 8}$ \\
\hline & UCT & WITS & UP \\
\hline SU & UP & UCT \\
\hline UKZN & UKZN & WITS \\
\hline & WITS & UNISA & NMMU \\
\hline & UNISA & UJ & UNISA \\
\hline & UP & NMMU & SU \\
\hline & RU & UCT & UJ \\
\hline & NMMU & SU & MI \\
\hline & NWU & NWU & UKZN \\
\hline 0 & UFS & RU & CPUT and RU \\
\hline
\end{tabular}

\subsection{Institutions Publishing in Prominent Categories}

In this section we briefly examine the publication trends of institutions in categories with more than 20 article counts (as identified in section 3). We also include a short discussion on a category that has emerged strongly during the last era.

\subsubsection{Computing Milieux}

Figure 17 illustrates the article counts over all institutions within the overall $\mathrm{K}$. Computing Milieux category. The most prominent institutions in this category are UCT, UP and UJ. 


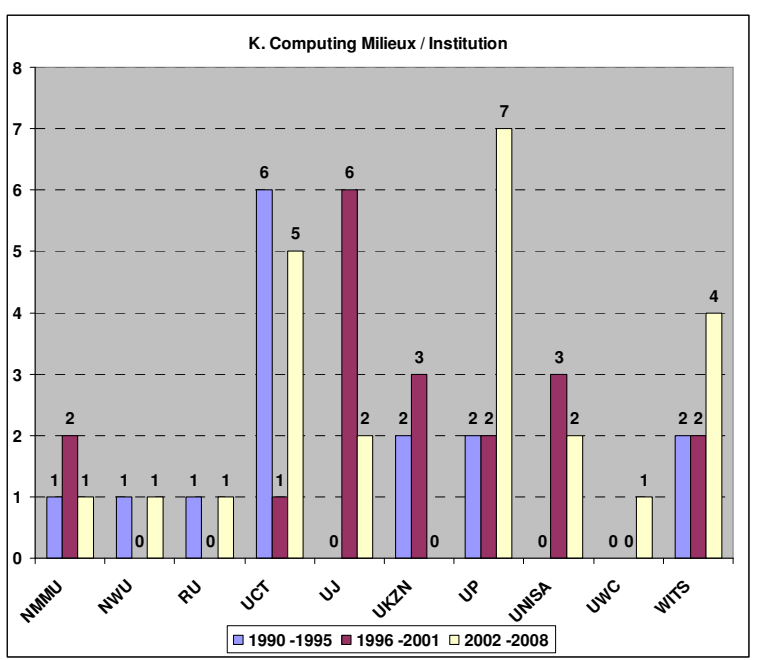

Figure 17. Computing Milieux article counts per institution

We analyse the Computing Milieux sub-subcategories for these three institutions in the remainder of this sub-section.

In analysing Figures 18 to 20 the data indicates that apart from the most prominent sub-subcategory between 1996 and 2008, namely K.6.5 Security and Protection, there is no overlap in the sub-subcategories between the three institutions. Within the Security and Protection subsubcategory UP's article counts peaked during the last era (2002 to 2008) and UJ during the middle era (1996 -2001). When one analyses the authors contributing to Security and Protection sub-subcategory it is obvious that the peak shift from UJ to UP was caused by two authors transferring from the former to the latter institution. Other strong subsubcategories are K.6.1 Project and People Management (UCT (all eras)), K.4.1 Public Policy Issues (only 2002 to 2008) and K.3.2 Computer and Information Science Education (1996 to 2008) both at UP.

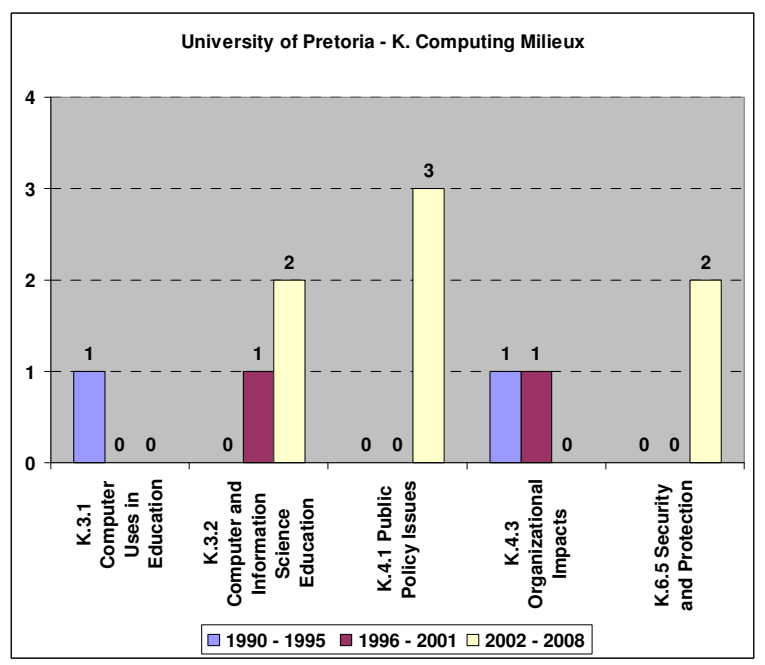

Figure 18. Computing Milieux sub-subcategory article counts for UP

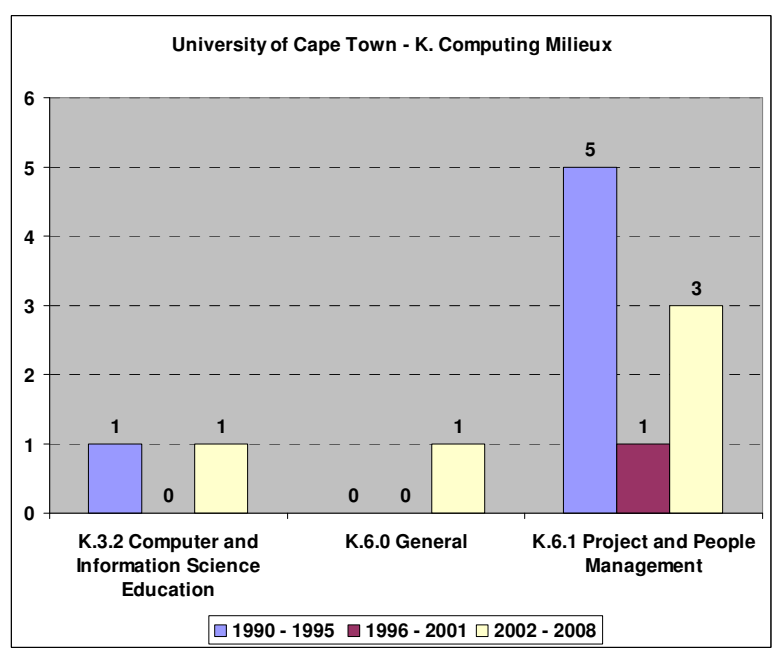

Figure 19. Computing Milieux sub-subcategory article counts for UCT

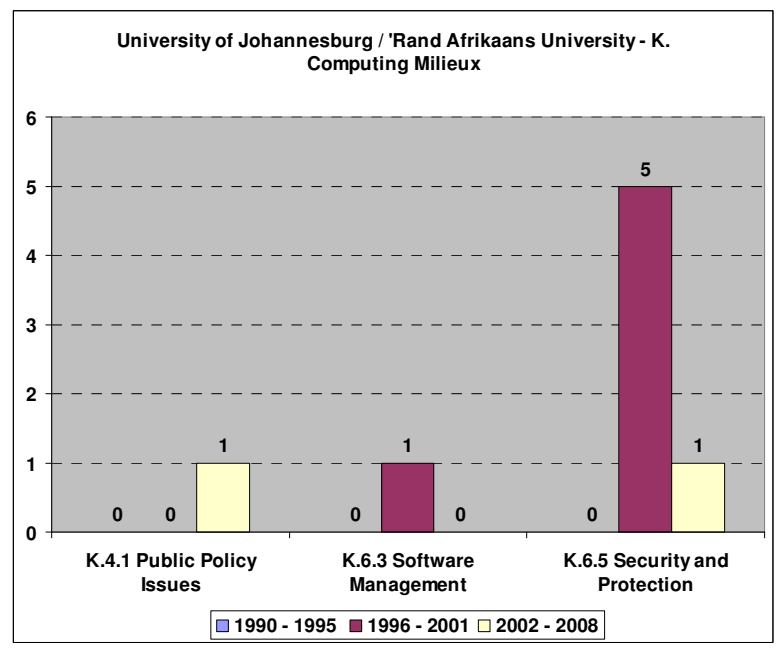

Figure 20. Computing Milieux sub-subcategory article counts for $\mathbf{U J}$

\subsubsection{Software}

Figure 21 illustrates the article counts over all institutions within the overall D. Software category. The most prominent institutions in this category are UCT, WITS, UKZN, and UP. The most prominent era for this category was 1990 to 1995 for the majority of institutions. 


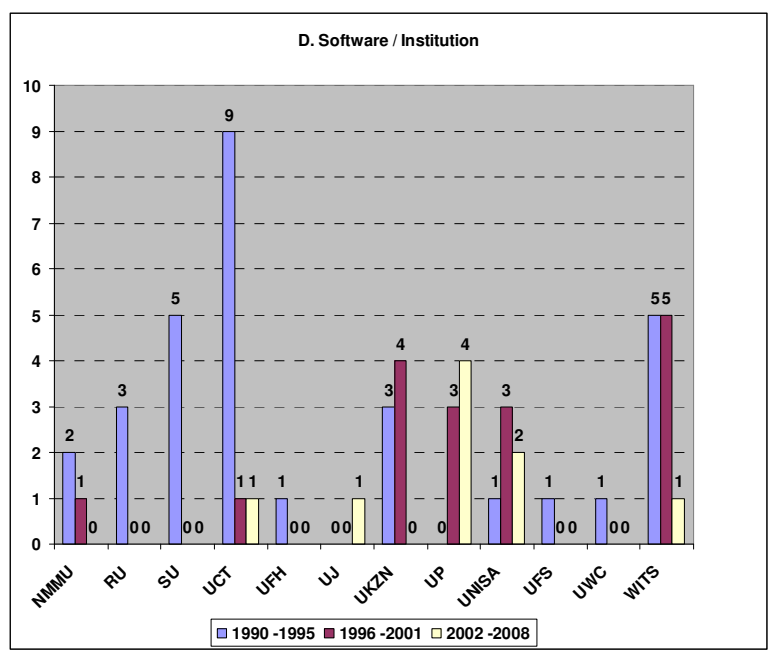

Figure 21. Software article counts per institution

In analysing Figures 22 to 25 the data indicates that no institution had a specific sub-subcategory within Software that it specifically focused on. The highest article count subsubcategory all over was D.1.4 Sequential Programming (3 article counts) at UP, where all 3 articles were contributed by the same author. UCT had 11 articles overall, all in the first two eras, and none in the last (2002 to 2008). The same trend is noticed at UKZN (all 7 articles) and WITS with only 1 out of a total of 11 articles during the last era.

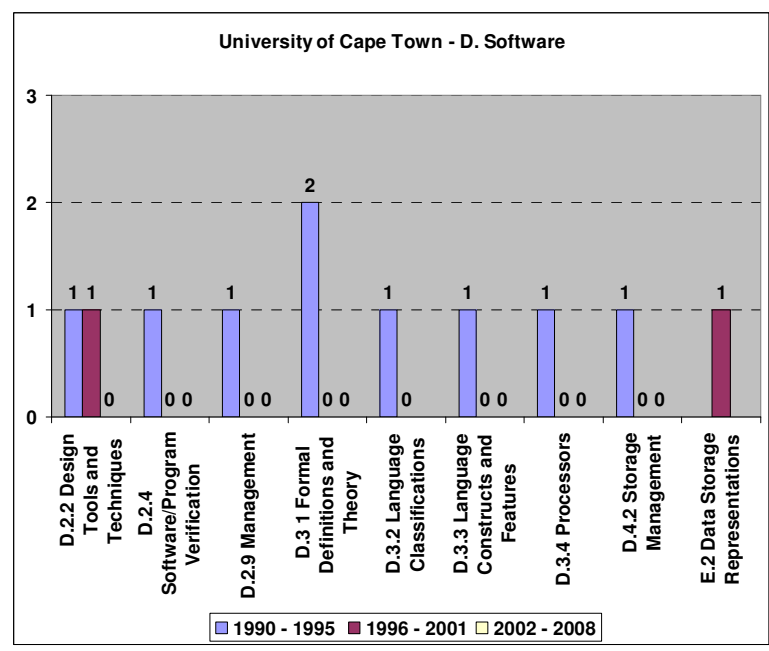

Figure 22. Software sub-subcategory article counts for UCT

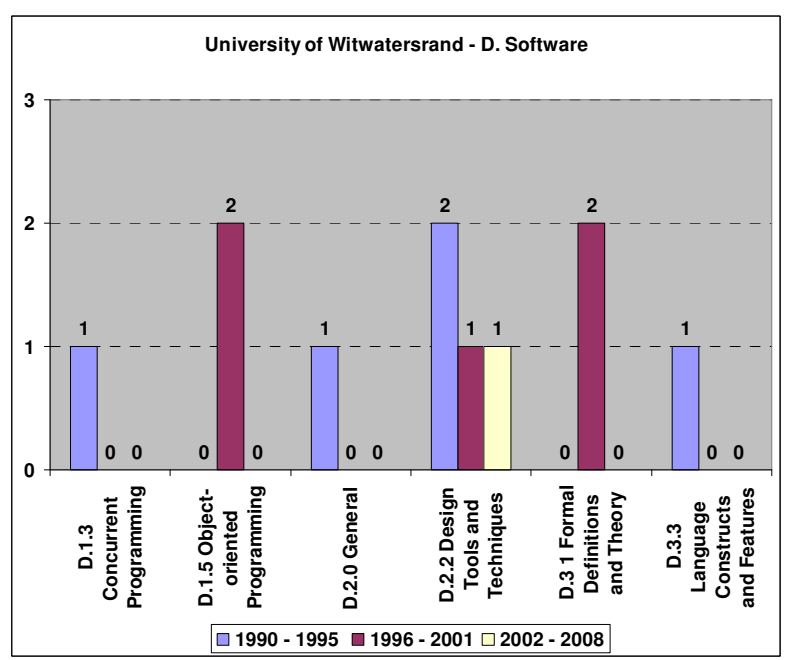

Figure 23. Software sub-subcategory article counts for WITS

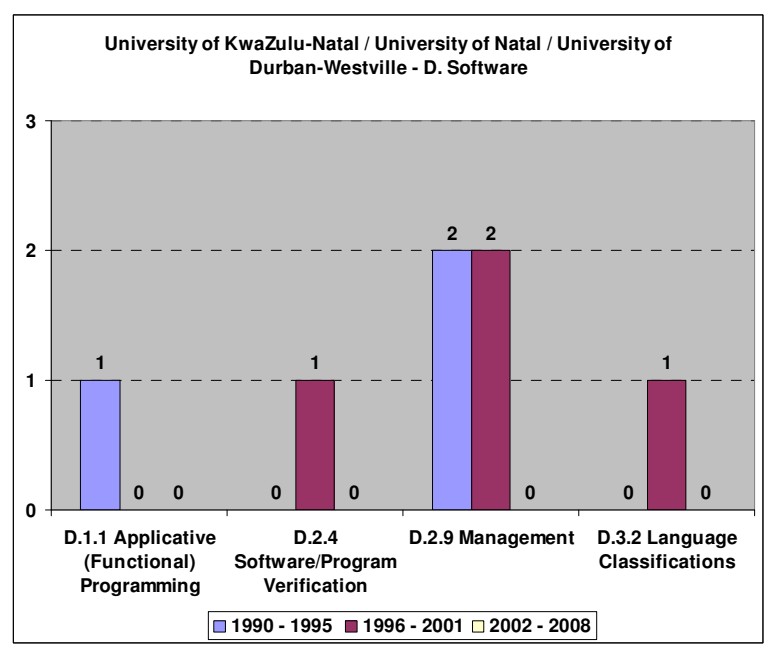

Figure 24. Software sub-subcategory article counts for UKZN

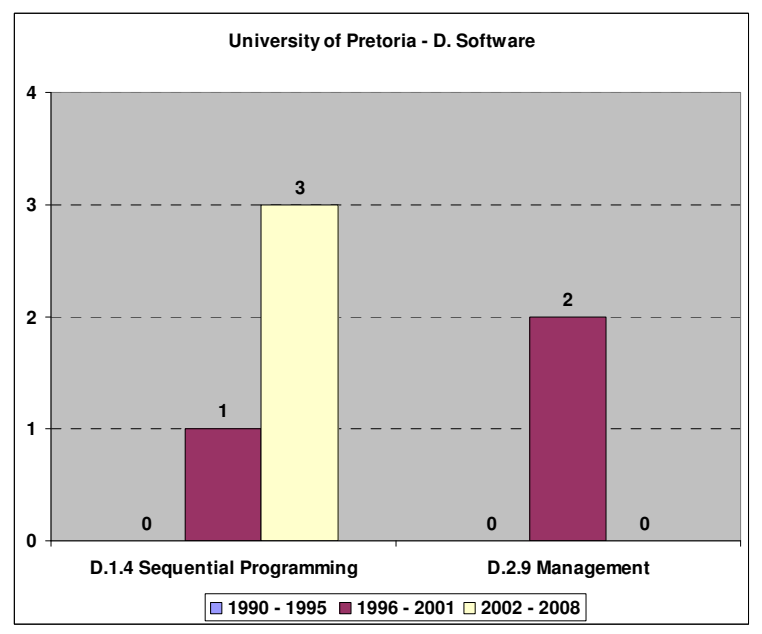

Figure 25. Software sub-subcategory article counts for UP 


\subsubsection{Information Systems}

Figure 26 illustrates the article counts over all institutions within the overall $\mathrm{H}$. Information Systems category. The most prominent institutions in this category are UCT, UKZN, UP, and NMMU. The most prominent era for this category varied for the individual institutions. The last era not only had the highest article counts but also the most institutions associated with the publications, including 3 newcomers.

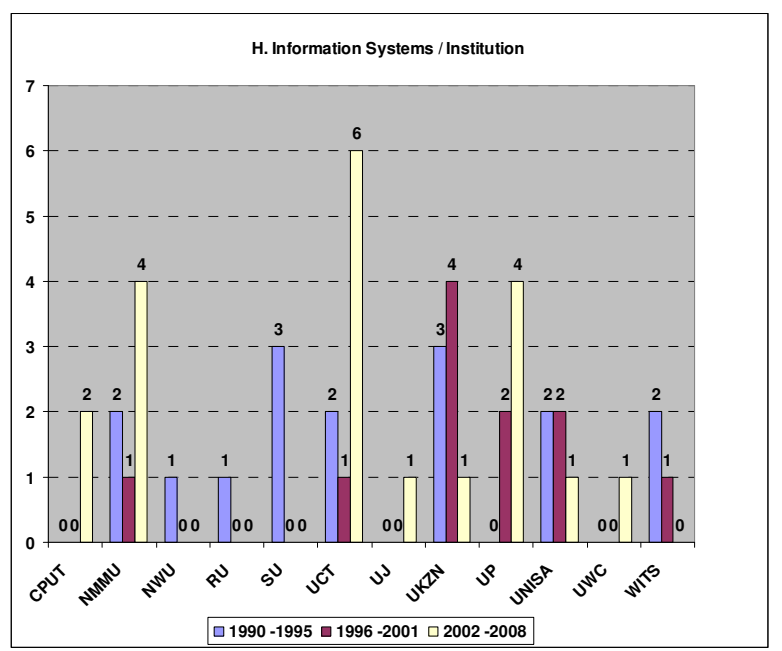

Figure 26. Information Systems article counts per institution

Analysing Figures 27 to 30 the data indicates that, like Software, no institution had a specific sub-subcategory within Information Systems that it focused on in the longterm. The highest article count sub-subcategory all over was H.5.2 User Interfaces (4 article counts, all in the last era (2002 to 2008)) at NMMU. UCT had 9 articles overall in 8 sub-subcategories, with 6 in the last era. In contrast UKZN had 8 articles overall, but only 1 in the last era. UP had articles in 4 sub-subcategories, with no eras overlapping.

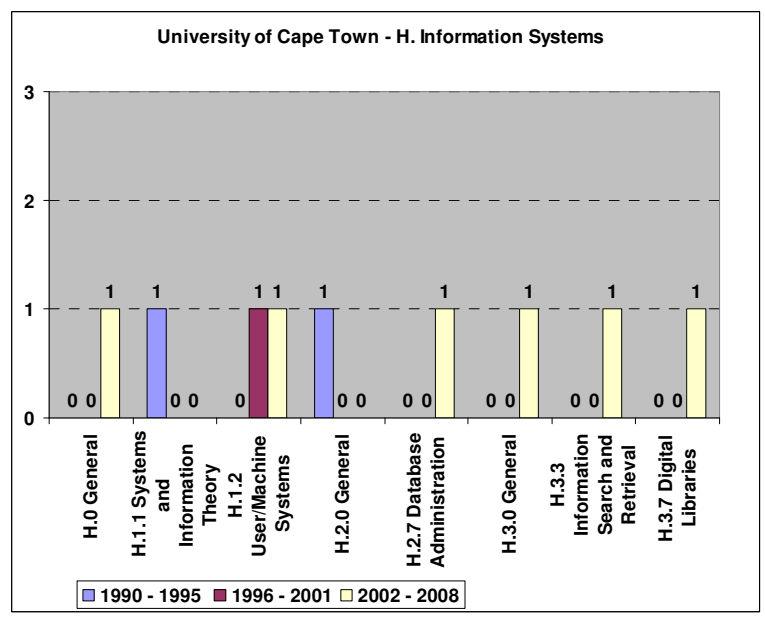

Figure 27. Information Systems sub-subcategory article counts for UCT

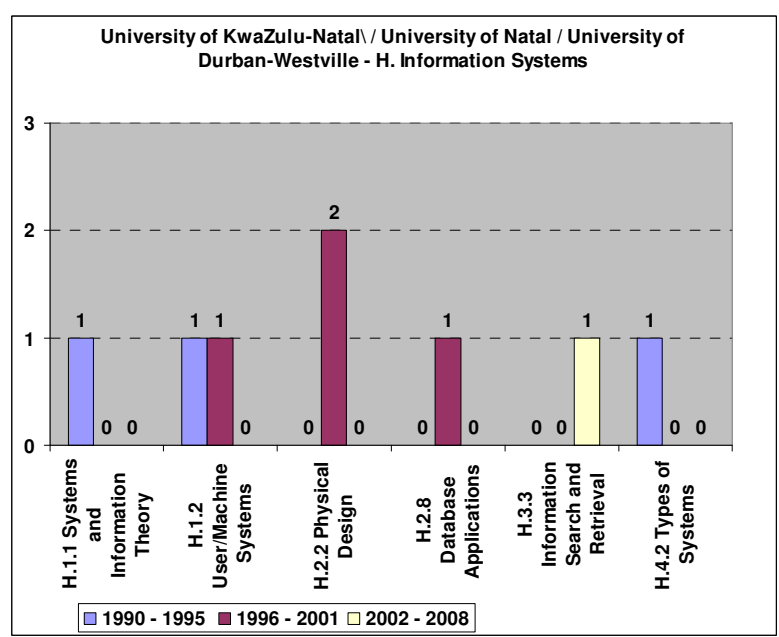

Figure 28. Information Systems sub-subcategory article counts for UKZN

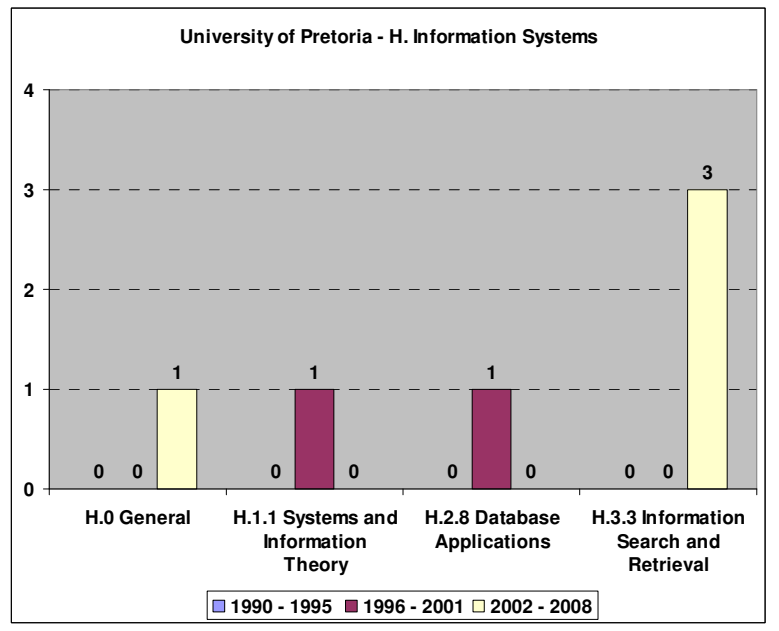

Figure 29. Information Systems sub-subcategory article counts for UP

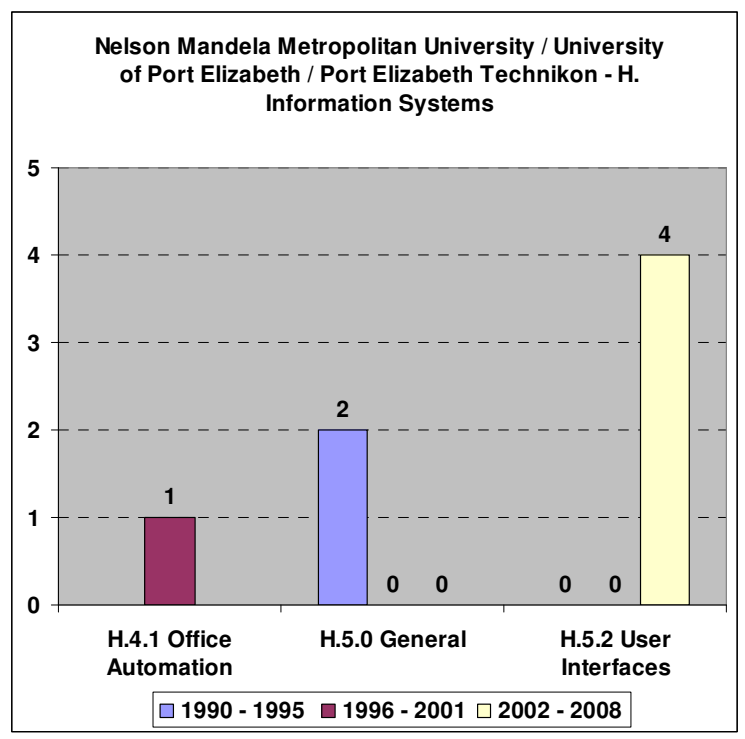

Figure 30. Information Systems sub-subcategory article 


\section{counts for NMMU}

\subsubsection{Computing Methodologies}

Figure 31 illustrates the article counts over all institutions within the overall I. Computing Methodology category. The most prominent institutions in this category are SU, UCT, UKZN, and UP. The most prominent era for this category varied by institution, with the first era being the most prominent for 3 of the 4 highest scoring institutions overall.

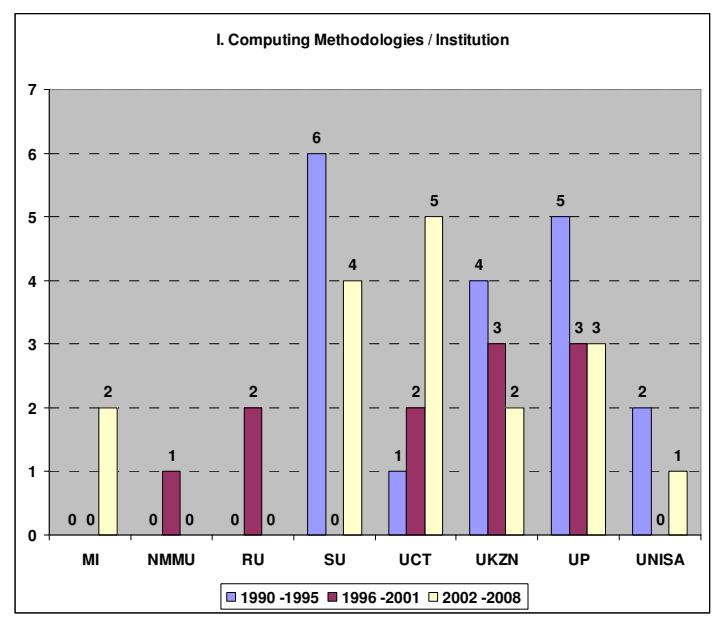

Figure 31. Computing Methodology article counts per institution

Analysing Figures 31 to 35, the data indicates that there was no focus in any specific sub-subcategory over the 4 most prominent institutions in the Computing Methodology category, apart from maybe I.2.1 Applications and Expert Systems at UKZN, with 4 articles spread over all three eras. Most institutions had articles in a variety of subsubcategories with very few such sub-subcategories even overlapping with those of other institutions. There are some overlap over institutions in I.4.6 Segmentation (3 articles), I.2.7 Natural Language Processing (3 articles).

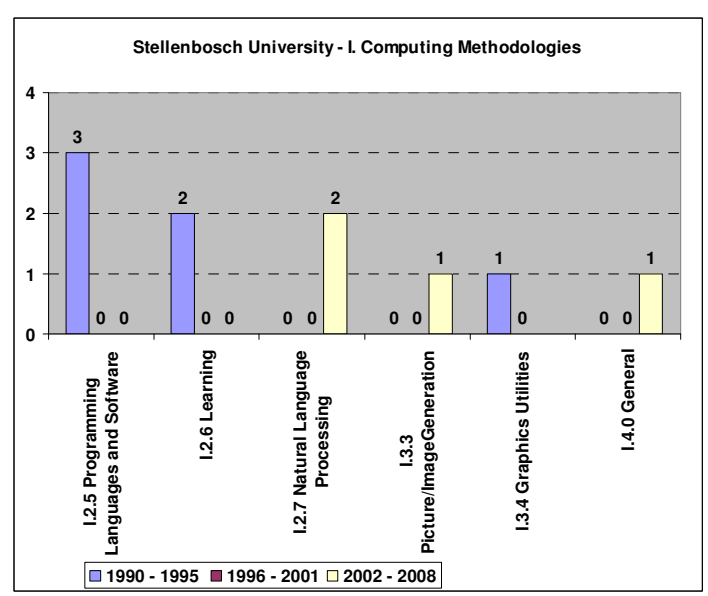

Figure 32. Computing Methodology sub-subcategory article counts for $\mathrm{SU}$

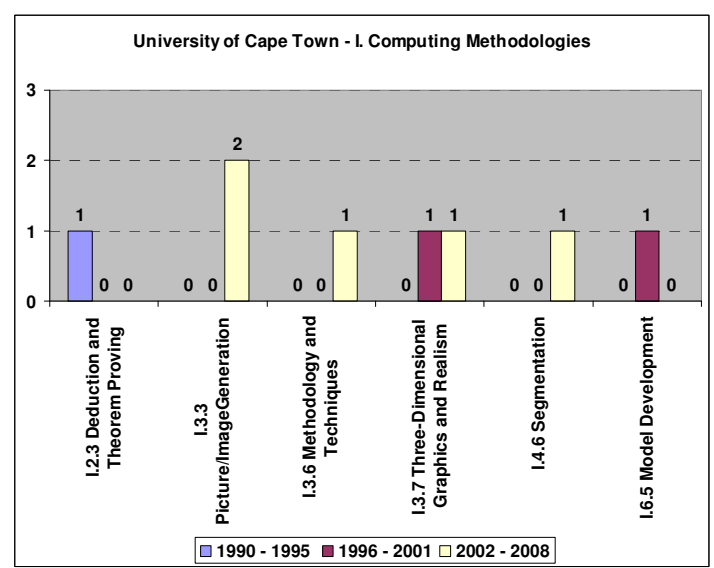

Figure 33. Computing Methodology sub-subcategory article counts for UCT

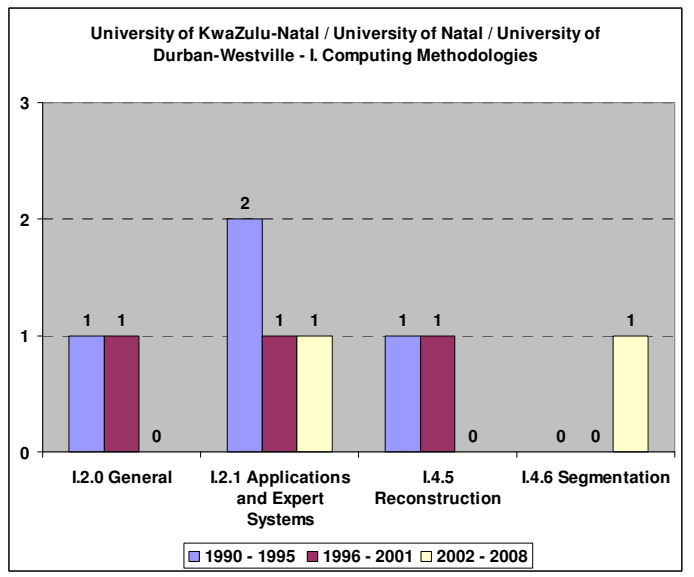

Figure 34. Computing Methodology sub-subcategory article counts for UKZN

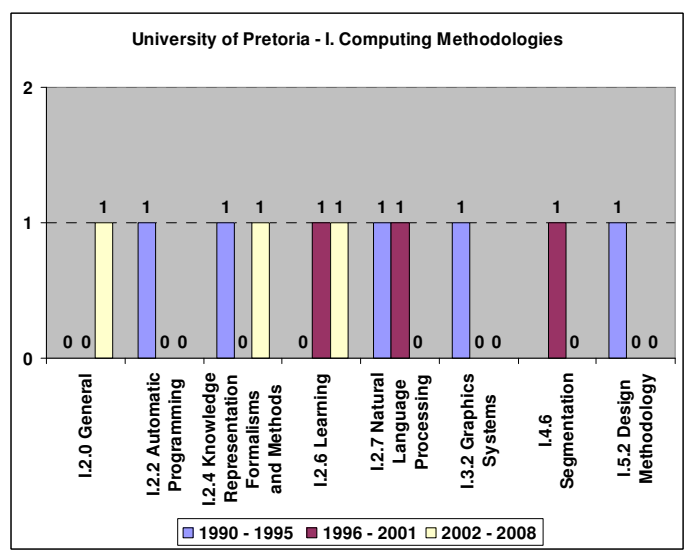

Figure 35. Computing Methodology sub-subcategory article counts for UP

To complete the discussion on institutions publishing in prominent categories, we will briefly in the next three subsections look at the following two categories in the ranking without analysing the subcategories of the individual institutions, as well as J. Computer Application which is emerging at 4 institutions. 


\subsubsection{Theory of Computation}

Figure 36 illustrates the article counts over all institutions within the overall $\mathrm{F}$. Theory of Computation category. The most prominent institutions in this category are the WITS (9 articles with 6 in the last era), UNISA(5 articles with 3 articles in the last era), and SU (5 articles with 2 in the last era). The most prominent era for this category varied by institution, with the first era being the most prominent for 3 of the 4 highest scoring institutions overall.

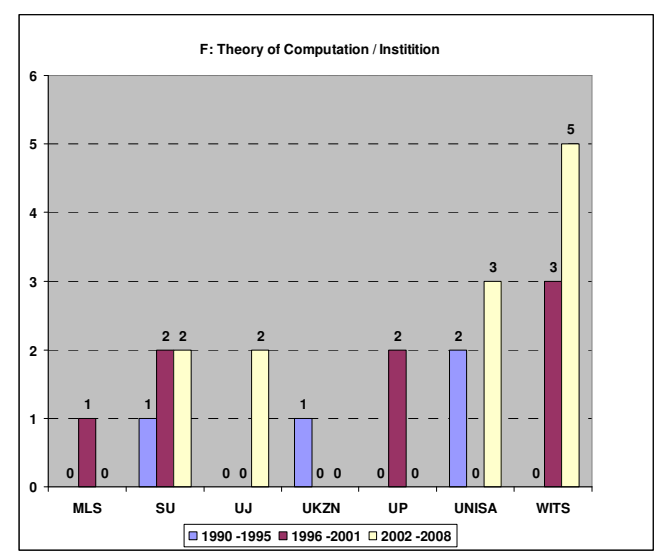

Figure 36. Theory of Computation article counts per institution

\subsubsection{Computer Systems Organization}

Figure 37 illustrates the article counts over all institutions within the overall C. Computer System Organization category. The most prominent institutions in this category are UP ( 5 articles with 3 in the last era) and UCT ( 5 articles with 4 articles in the first era). This category has been prominent in several institutions during the first era, but then declined overall, except for UP.

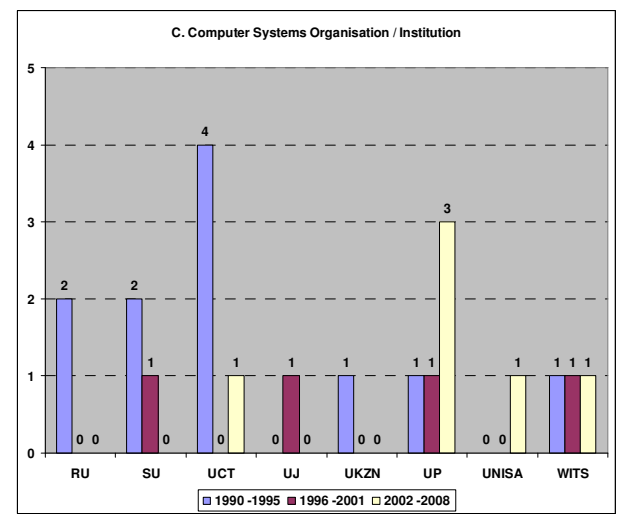

Figure 37. Computer System Organization article counts per institution

\subsubsection{Computer Applications}

Figure 38 illustrates the article counts over all institutions within the overall J. Computer Applications category. This category has becoming prominent in a variety of institutions during the last era. The institutions contributing to this in this category are the MI ( 3 articles), UP ( 3 articles), WITS (2 articles), and RU (1 article).

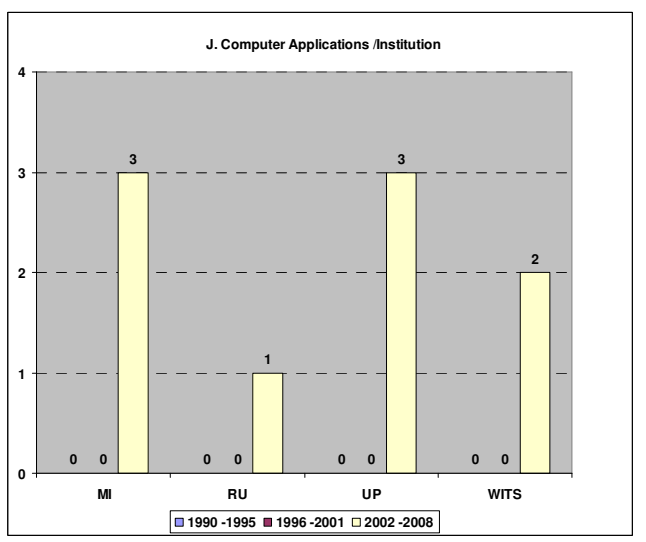

Figure 38. Computer Application article counts per institution

\subsection{Categories per Institution}

This section focuses on individual institutions in relation to the categories in which the institution published over all three eras. We only include those institutions appearing in the top 5 overall or in any era.

\subsubsection{University of Cape Town}

The total 50 articles published by UCT were distributed over the majority of the categories (excluding General Literature, Data, and Computer Applications). The most prominent categories were Computing Milieux (strong during first and last era), Software (strong in first and second era, with big decline in last era), Information Systems (strong in last era), Computing Methodologies (strong in last era), and Computer System Organization (strong in first era, with big decline since). There thus seems to be a shift from the more theoretical fields to the more applied categories at this institution. Overall there has been a decline in total article count during the middle era (from 24 to 6), with a growth to 20 in the third era.

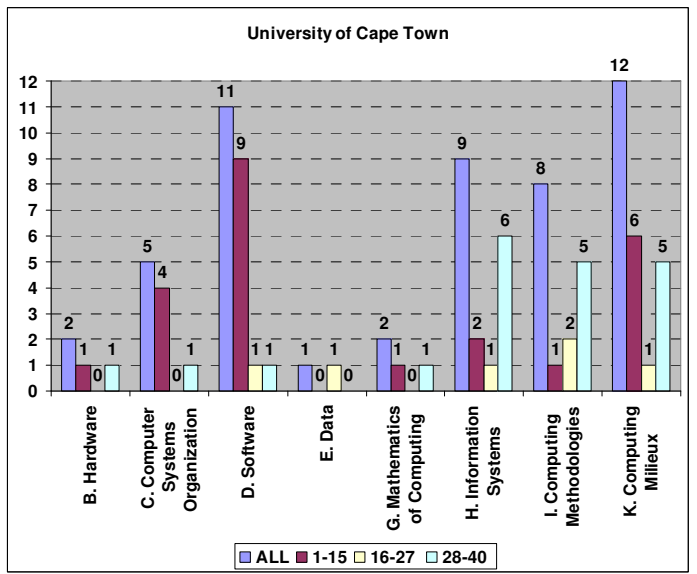

Figure 39. Category counts for UCT

\subsubsection{University of Pretoria}

Of the 49 articles by UP overall, Computing Methodologies and Computing Milieux have been the most prominent categories with 11 articles each, the former declining from the first to the second era, with the latter growing strongly 
during the last era. Other prominent categories over time include Software (growing since second era), Information Systems (growing since second era), and Computer System Organization (active in all eras but growing in third era). The institution has been active in most categories apart from General Literature and Data. The total article counts grew from 8 in the first era, 15 in the second era, to 26 in the third era.

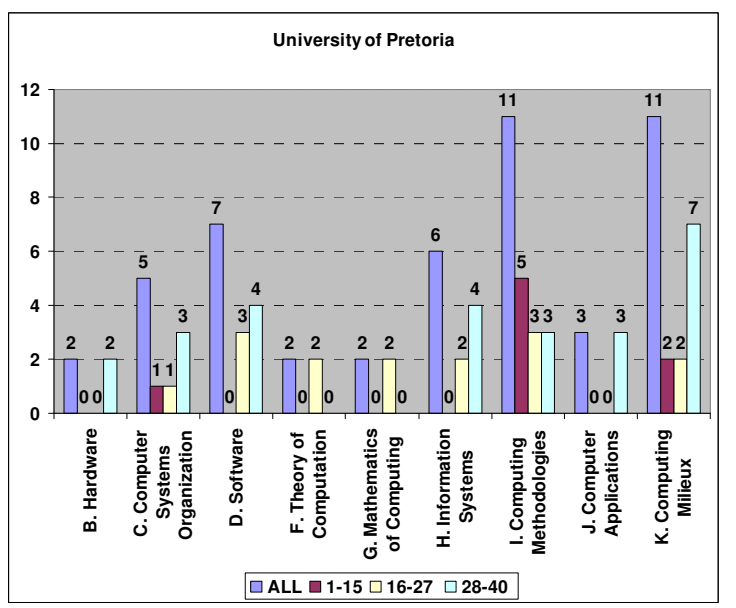

Figure 40. Category counts for UP

\subsubsection{University of Witwatersrand}

The Software category, with 11 articles has been the most prominent in the total of 44 articles published by WITS. The category was strong in first and second eras with a big decline in the third era. This is followed with 8 articles each in the Theory of Computation and Computing Milieux categories, both growing in the third era, and the Computing Methodologies category with 5 articles during the first and second eras. The institution published smaller numbers of articles in all the remaining categories except for Data. The total number of article counts has remained fairly stable over all three eras, namely 13,16 , and 15 .

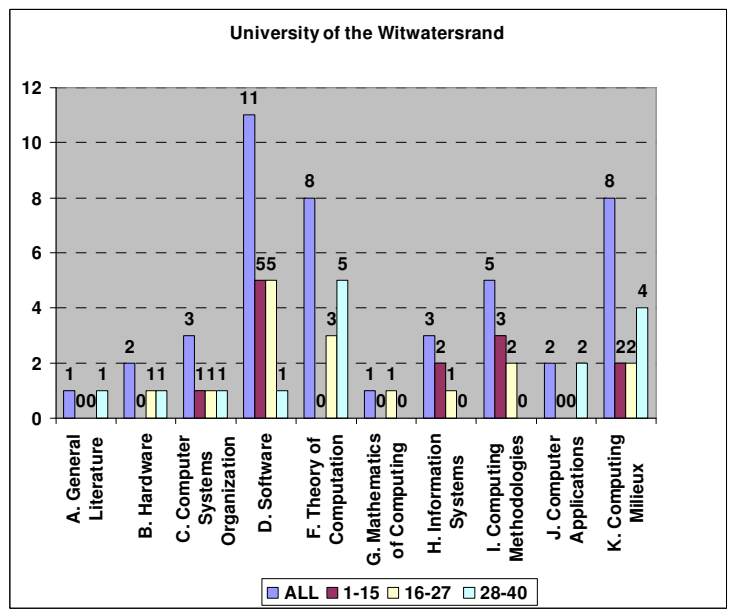

Figure 41. Category counts for WITS

\subsubsection{University of University of University of KwaZulu-Natal / University of Natal / University of Durban-Westville}

UKZN published 34 articles overall with Computing Methodologies (slowly declining) the highest category with 9 articles. This category is followed by Information Systems (8 articles), Software (7 articles), Computing Milieux (5 articles), all declining / disappearing during the last era. The institution published in all categories except Hardware and Computer Applications. The overall article count dropped during the three eras, from 16 during the first era, 14 during second era, to 4 in the last era.

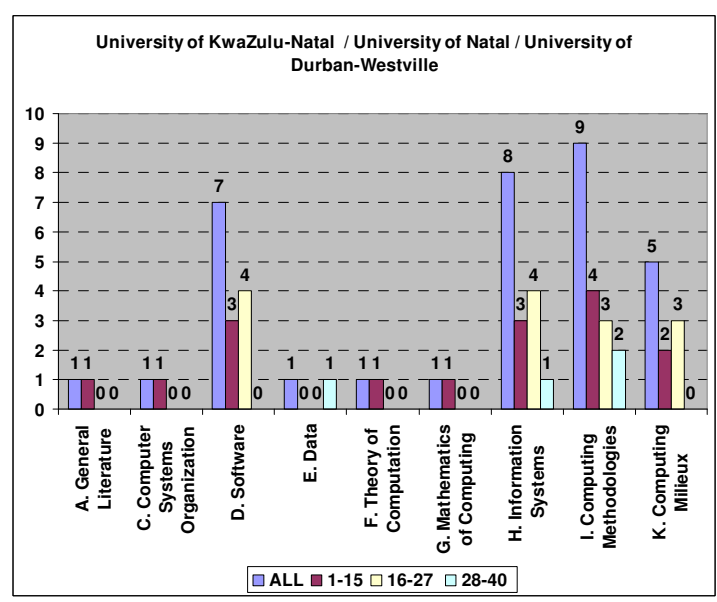

Figure 42. Category counts for UKZN

\subsubsection{University of South Africa}

Of the 28 articles published by UNISA, the Software category was the most prominent ( 6 articles), followed by 5 articles each for Theory of Computation (no articles in second era), Information Systems and Computing Milieux (no articles in first era). The institution published in all categories except Hardware, Mathematics of Computing, and Computer Applications. The total number of article counts has remained stable over the three eras, namely 9, 9, and 10 .

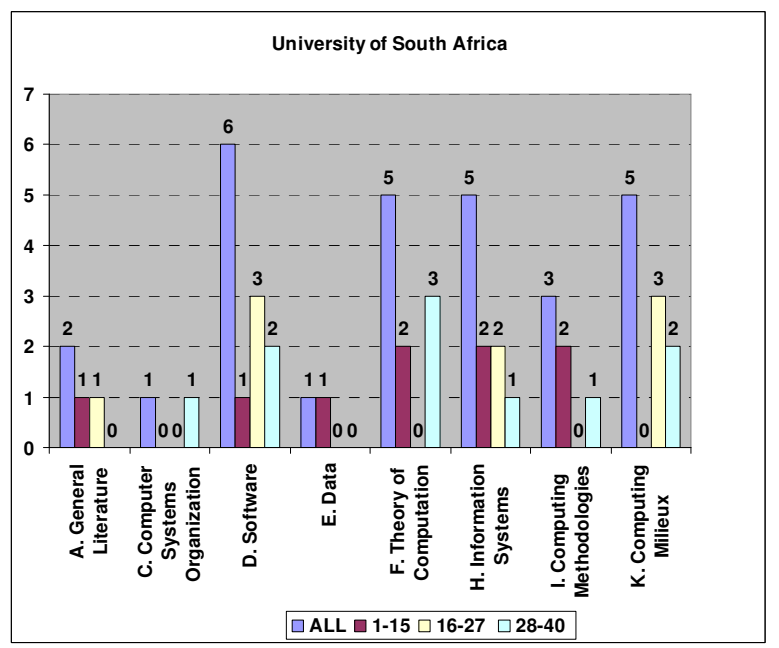

Figure 43. Category counts for UNISA 


\subsubsection{Stellenbosch University}

The SU has a total of 27 articles in total with 10 of these in the Computing Methodologies category, following with 5 each in the Software and Theory of Computation categories, the latter the only non-declining category. The institution published in 6 of the 11 categories. Overall there has been a large decline in total article count during the middle era (from 17 to 3), with a growth to 7 in the third era.

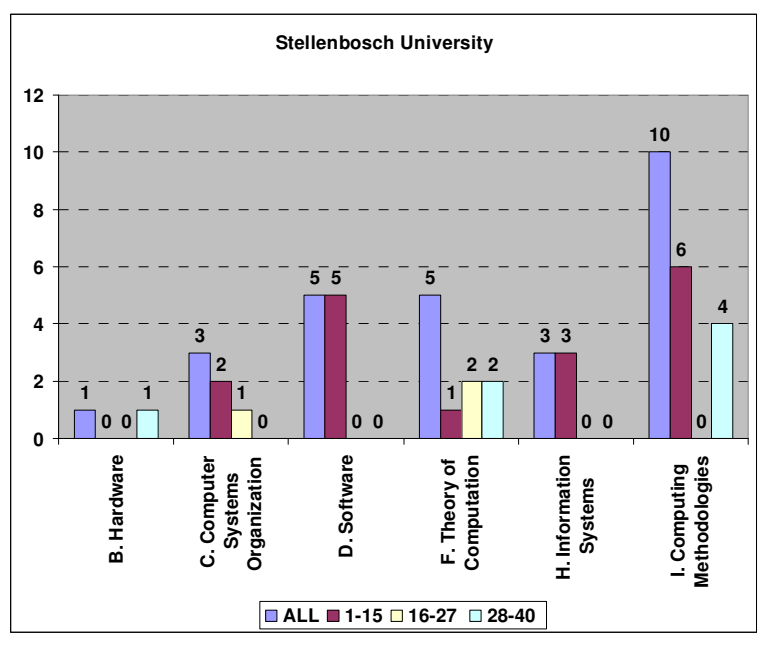

Figure 44. Category counts for SU

\subsubsection{Nelson Mandela Metropolitan University I University of Port Elizabeth / Port Elizabeth Technikon}

NMMU published a total of 15 articles overall, with a slow growth over the three eras (4, 5 and 6 articles respectively). The most prominent category within these articles has been Information Systems ( 7 articles with a growth in the third era), Computing Milieux (4 articles) and Software (3 articles declining over the three eras). The institution published in 6 of the 11 categories.

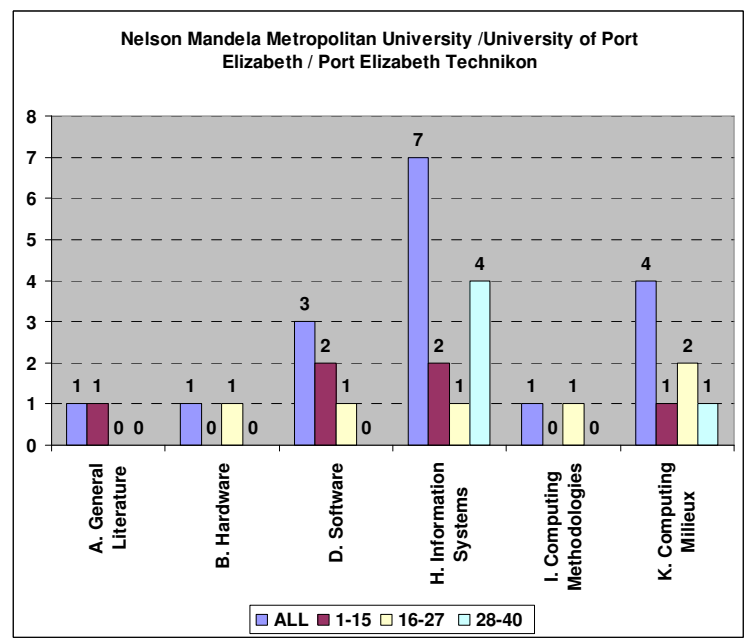

Figure 43. Category counts for NMMU

\section{CONCLUSION}

We gave an overview and summary of all the research articles published in SACJ since its inception, i.e. all research articles published in the 40 volumes of SACJ since its first publication in 1990. We used the ACM Computing Classification Systems to categorise the articles. We first analysed the articles according to the first and second levels of this scheme, and down to a few third level categories for particular trends we observed. We also analysed the major publication trends of South African tertiary education and research institutions according to this classification scheme.

A total of 344 articles that could be classified as research articles were used in the analysis. Of these $21.22 \%$ were published within the Computing Milieux category. The most significant subcategory within the Computing Milieux category was Management of Computing and Information Systems (41 articles), Computers and Society (24 articles) and Computers and Education ( 8 articles). The second most articles $(19.48 \%)$ were published in the Software category with the most articles in the Software Engineering subcategory (42 articles). In third position was the Information Systems category (16.57\%) where the focus was primarily on articles in the Database Management subcategory. This is however a declining trend since 17 of the 18 articles in this subcategory was published in the first two eras of SACJ. The last major category was the Computing Methodologies category (15.99\%). The subcategory where a significant number of articles were published is the Artificial Intelligence category with a total of 31 articles. However, the majority of articles in this category were published in the first era of SACJ. The remainder of the categories each covered less than $8 \%$ of the total number of research articles published in SACJ.

With regard to trends within sub-subcategories, Computer Communication Networks, Information Systems (General), Information Search and Retrieval, User Interfaces, and Natural Language processing were the five categories with a growing trend over the 19 year period. In contrast, the declining categories over all the eras were Design Tools and Techniques, Project and People Management, Distributed Systems, Management, and Language Constructs and Features. The stable categories were Requirements / Specifications, Mathematical Logic, User / Machine Systems, and Applications and Expert Systems. It is also interesting to note the sub-subcategories that peaked in the middle era, but declined in the last era, namely, Security and Protection Software/Program Verification, and Computer and Information Science Education. The various eras thus had some specific focus areas.

With regard to institutions, the top three institutions (according to articles counts) that published in the first 40 volumes of SACJ were UCT, UP and WITS, all with more that 40 research articles. They are followed by UKZN, UNISA and SU with more than 25 articles each. Insofar as top 5 ranking over the eras is concerned, UKZN and SU have both lost ground and have been replaced by NMMU in the last era. None of the institutions had a particular category focus over all the eras, although some subcategories were more prominent in some of the individual eras than in others. Examples include Security and Protection at UJ during the second era and UP during the last era, Project and People Management (UCT all eras), Public Policy Issues (UP last era), Computer and 
Information Science Education (UP last two eras), and User Interfaces (NMMU last era).

Although the data for the authors is not included in this paper, the author with the most research articles published in the first 40 volume of SACJ was Martin (MS) Olivier (first at Rand Afrikaans University and later University of Pretoria) with 8 articles, followed by Jan (JHP) Eloff (also first at Rand Afrikaans University and later University of Pretoria, Andries (AP) Engelbrecht (University of Pretoria) and Ian Cloete (Stellenbosch University) all with 6 articles each. While the first three of these authors published during the middle and last eras, Cloete's publications were all during the first era.

From our analysis one can derive that the first 40 editions of SACJ did represent a significant number of research areas within Computing. The growing trends of articles in applications areas such as Life and Medical Sciences and Arts and Humanities, gives an indication that SACJ did not limit the scope of publications to pure Computer Science articles only; although the stable categories resides in this area. A problem may be the decline in articles within the Design Tools and Techniques as well as the Project and People Management area, since both these categories are important in the growing field of Computing. An interesting observation is the decline in Distributed Systems, but a simultaneous growth in Computer Communication Networks and Information Search and Retrieval. This change in focus might be due to the explosion of the Internet and the World Wide Web, and the supporting networks and retrieval of Information within this field. Furthermore, the growth of research with regard to User Interfaces might relate to the recognition of human-computer interaction (HCI) as an emerging research field within Computing. The same applies to the fields related to human language technologies (Natural Language Processing and Arts and Humanities subsubcategories) and bioinformatics (Life and Medical Sciences sub-subcategory).

A question that we did not try to answer in our analysis, and which could be the topic of follow-up research, is whether the trends and articles published in SACJ is a reflection of the research landscape of computing research in South Africa. Does it reflect the history of computing in South Africa? If it is not representative, the reasons why should be determined. Is it because SACJ is not seen as a high quality journal? Is it because of the low citation rates of articles published in SACJ (perhaps because it is too well hidden within SABINET and therefore not easily accessible and not picked up by search engines)? Is it because it is not an openaccess journal? Is it because of editorial policies? If it is representing the research landscape, how can the new editor make sure that it stays representative and become an even stronger voice of computing in South Africa?

\section{ACKNOWLEDGMENTS}

We wish to thank Mariaan Loock for her input in the conceptualization of the paper, Derick van der Merwe for construction of the database and queries, and Mabel Campher for the data capturing.

\section{REFERENCES}

[1] ACM: Computing Classification System. (1998) [cited 12 September 2008]; Available from: http://www.acm.org/class/.

[2] BBC News: Green light for EU science plan. (2006) [cited 2007 August 2007]; Available from: http://news.bbc.co.uk/2/hi/science/nature/6190160.stm.

[3] Birchwood Declaration: Birchwood Decleration for Tertiary Level ICT Skills Development. (2007) [cited November 2008]; Available from: http://www.cs.ru.ac.za/ICTSkills/Declaration\%20ICTSkills\%202007.pdf.

[4] Casey, L.: South African Computer Journal to go Online. (2001) [cited 2006 January 2007]; Available from: http://blues.sabinet.co.za/comp/.

[5] Glass, R.L., Ramesh, V., Vessey, I.: An analysis of Research in Computing Disciplines. Communications of the ACM. 47(6) (2004), 89-94.

[6] Goth, G.: Stepping up to long-term research. IEEE distributed systems. 8(10) (2007).

[7] Government of the Republic of South Africa: South Africa's National Research and Development Strategy. (2002) [cited 12 September 2008]; Available from: http://www.pub.ac.za/resources/docs/sa_rd_strat_2002. pdf.

[8] Meraka Institute: Meraka Institute Web Pages. (2007) [cited September 2008]; Available from: http://www.meraka.org.za/.

[9] Roode, D.: It is time for IS to understand its history. SACJ. 40(June 2008) (2008), 1-2.

[10] SACJ: South African Computer Journal Website. (2007) [cited 2007 September]; Available from: http://www.journals.co.za/ej/ejour_comp.html.

[11] SAICSIT: Annual Conference of the South African Institute of Computer Scientists and Information Technologists. (2008) [cited September 2008]; Available from: www.nmmu.ac.za/saicsit/.

[12] The Joint Task Force for Computing Curricula 2005: Computing Curricula 2005 - The Overview Report. Computing Curricula Series (2005) [cited 12 September 2008]; Available from: http://www.acm.org/education/education/curric_vols/C C2005-March06Final.pdf. 